Effect of Shock Compression Method on the Defect Substructure in

Monocrystalline Copper

B. Y. Cao, M. A. Meyers, D. H. Lassila, M. S. Schneider, B. K. Kad, C. X. Huang, Y. B. Xu, D. H. Kalantar, B. A. Remington

March 3, 2005

TMS 2005 134th Annual Meeting \& Exhibition San Francisco, CA, United States February 13, 2005 through February 17, 2005 
This document was prepared as an account of work sponsored by an agency of the United States Government. Neither the United States Government nor the University of California nor any of their employees, makes any warranty, express or implied, or assumes any legal liability or responsibility for the accuracy, completeness, or usefulness of any information, apparatus, product, or process disclosed, or represents that its use would not infringe privately owned rights. Reference herein to any specific commercial product, process, or service by trade name, trademark, manufacturer, or otherwise, does not necessarily constitute or imply its endorsement, recommendation, or favoring by the United States Government or the University of California. The views and opinions of authors expressed herein do not necessarily state or reflect those of the United States Government or the University of California, and shall not be used for advertising or product endorsement purposes. 


\title{
EFFECT OF SHOCK COMPRESSION METHOD ON THE DEFECT SUBSTRUCTURE IN MONOCRYSTALLINE COPPER*
}

\author{
Bu Yang Cao ${ }^{1}$, Marc A. Meyers ${ }^{1}$, David H. Lassila ${ }^{2}$, Matt S. Schneider ${ }^{1}$, Bimal K. Kad ${ }^{1}$, \\ Chong Xiang Huang ${ }^{3}$, Yong Bo $\mathrm{Xu}^{3}$, Daniel H. Kalantar ${ }^{2}$, Bruce A. Remington ${ }^{2}$ \\ ${ }^{1}$ Materials Science and Engineering Program, University of California, San Diego, 9500 Gilman Dr., \\ UCSD 0411, La Jolla, CA 92093 USA \\ ${ }^{2}$ Lawrence Livermore National Laboratory, Livermore, CA 94550 USA \\ ${ }^{3}$ Chinese Academy of Sciences, Shenyang Natl. Lab. for Matls. Sci., Inst. of Metal, Shenyang, Liao Ning \\ 110016 China
}

\begin{abstract}
Monocrystalline copper samples with orientations of [001] and [221] were shocked at pressures ranging from $20 \mathrm{GPa}$ to $60 \mathrm{GPa}$ using two techniques: direct drive lasers and explosively driven flyer plates. The pulse duration for these techniques differed substantially: $2 \mathrm{~ns}$ for the laser experiments and $1.1-1.4 \mu \mathrm{s}$ for the flyer-plate experiments. The residual microstructures were dependent on orientation, pressure, and shocking method. The much shorter pulse duration in laser shock yielded recovery microstructures with no or limited dislocation motion. For the flyer-plate experiments, the longer pulse duration allow shock-generated defects to reorganize into lower energy configurations. Calculations show that the post shock cooling occurs in a time scale of $0.2 \mathrm{~s}$ for laser shock and $1000 \mathrm{~s}$ for plate-impact shock, propitiating recovery and recrystallization conditions for the latter. At the higher pressure level extensive recrystallization was observed in the plate-impact samples, while it was absent in laser shock. An effect that is proposed to contribute significantly to the formation of recrystallized regions is the existence of micro-shearbands, which increase the local temperature.
\end{abstract}

Keywords; laser, shock compression, plate impact, shear localization in copper, shock waves, explosives

* Submitted for the TMS Symposium: Micromechanics of Advanced Materials II, in Honor of James C.M. Li's 80 ${ }^{\text {th }}$ Birthday, February 13-17, 2005, San Francisco, CA. 


\section{Introduction}

It is indeed a distinct honor to give a presentation in this symposium and to author a paper commemorating this festive occasion. The principal theme of Prof. J. C. M. Li's work has been micromechanisms of mechanical behavior in crystalline and amorphous materials (metals, metallic glasses, porous materials, and polymers). The nature of his work has been both theoretical and experimental. Professor Li is undoubtedly one of the global authorities in this field, and his contributions have spanned fifty years. The contributions of Prof. Li have covered a broad range of activities within the field of mechanical behavior of materials. Among the numerous original inroads into heretofore unchartered territory, the following come to our mind:

- Mechanism for plastic deformation of metallic glasses (e. g. [1-4])

- Shear localization in metallic glasses (e.g. [2-4])

- Mechanism for the grain-size dependence of yield stress (e.g. [5])

- Use of impression testing using micron-sized cylindrical indenters to determine adhesion, creep resistance, viscosity, and the kinetics of stress relaxation (e.g. [6])

- Dislocation dynamics through stress relaxation (e. g. [6,7])

- Combustion synthesis of intermetallic compounds (e.g. [8])

- Thermally-activated description of plastic flow (e.g. [9])

Shock compressed materials show a great variety of microstructures. The effects of the uniaxial-strain high-strain-rate loading have been studied for the past 50 years. Smith [10] first described the shock compression of materials in mechanistic terms. In the early techniques, samples were subjected to shock compression by explosives, either by direct loading or by impact. The samples were recovered and the microstructure was analyzed to evaluate the effects of the shock pre-straining on the material. Later, different kinds of experiments have been designed to investigate the dynamic behavior of different materials [11-15].

Recovery experiments provide a convenient way to study defect generation and energy storage mechanisms in materials subjected to shock waves especially given the difficulty involved in studying the physical properties of the materials during shock (rapid loading rate and short time interval). Since that time, much work has been done on 
quite a number of materials to develop a hydrodynamic understanding of the material behavior, and several reviews have summarized the systematic changes in the structureproperty relationships generated by shock wave passage through the material [16, 17]. Most of this work correlates the microstructure and mechanical property changes to the compression characteristics like peak pressure, pulse duration, rarefaction rate and even temperature. Also, much work has been done to model these responses and to compare the behaviors to those observed at low strain rates [16-18]. Remington et al. [19] review the most significant recent work.

For the experimental techniques of shock compression, it is essential that the principal parameters be well characterized in the experiments. Flyer-plate impact and laser shock are two typical loading methods employed in shock-recovery experiments. In the flyer-plate impact experiment, the plate impacts a target at a known velocity. If the impact is perfectly plane and if the velocity vector of the impacting plate is perfectly normal to the impact plane, then a state of pure one-dimensional strain will be produced in both flyer plate and target. The very high strains undergone by copper jets in shaped charges have been attributed to a lateral inertia by Gray [20], Fressengeas and Molinari [21], and Romero [22].

Lasers deliver high amounts of energy in extremely short pulse durations enabling research in regimes of pressure and strain rates never before explored. Lasers have been shown to generate pressures from 10 to $500 \mathrm{GPa}$. Lasers also provide an easy way to vary pulse duration with picosecond resolution, which can then be correlated to the pressure data to yield a strain rate. Lasers typically produce less residual strain as compared to other techniques and post-shock heating is minimized because of the rapid quenching of the material due to the short pulses and specimen size/geometry. Laser-driven shock pulses are created by the rapid heating of the surface from the photon bombardment of the material [23].

Both of the flyer-plate impact [24] and laser [25] techniques have recently been employed to explore the post-shocked microstructures of monocrystalline copper. Significant differences in the residual microstructure have been observed at high pressures. 
It is the objective of this paper to demonstrate that the differences of the residual microstructures (which are orientation dependent) are to a large extent due to how the heat generated inside the samples during shock is extracted. Post-shock recovery and recrystallization processes dominate the residual microstructures, if time and temperature are sufficient.

\section{Experimental Methods}

Explosively driven flyer plates and direct drive lasers produce different shock pulses. Figure 1 shows the characteristic shapes of these two shock waves. The shock wave produced by plate impact has initially a square shape (Fig. 1(a)) [24]. It has a flat top that has a length equal to twice the time required for the wave to travel through the projectile. The portion of the wave in which the pressure returns to zero is called the "release". During impact, elastic waves with velocity $\mathrm{C}_{0}$ and shock waves with velocity $\mathrm{U}_{\mathrm{s}}$ are emitted into the target and projectile. For the experiments reported herein, the duration of the pulse at a depth of $5 \mathrm{~mm}$ from the impact interface was in the $1.1-1.4 \mu \mathrm{s}$ range. Pulsed lasers produce shock waves that do not have a flat top. A typical pulse shape is shown in Fig. 1 (b). The pulse duration is $2 \mathrm{~ns}$, at an energy is around $300 \mathrm{~J}$, which produces an initial pressure of approximately $60 \mathrm{GPa}$. In our experiments, phase plates were also utilized to smooth the beam over the entire surface of interest. Thus, the difference in duration is by a factor between 100 and 1000 .

In the explosion-driven flyer plate experiments, two orientations of monocrystalline copper, $<001>$ and $<221>$ were shock-compressed in the shock/recovery experiments at low temperature $(88 \mathrm{~K})$. The setup used for this experiment is shown in Figure 2(a). It is described in detail by Lassila et al. [24]. The copper samples were shocked by an explosion-driven flyer plate, providing an initial pulse duration of $1.4 \mu$ s for $30 \mathrm{GPa}$ and $1.1 \mu \mathrm{s}$ for $60 \mathrm{GPa}$. The monocrystalline cylinders, with a diameter of $20 \mathrm{~mm}$ and thickness of $4.5 \mathrm{~mm}$, were embedded in a copper plate (Fig. 2 (b)). Lateral and bottom momentum traps were employed to trap the lateral release waves and to prevent spalling of the copper. These traps were made from a $\mathrm{Cu}-\mathrm{Be}$ alloy because of its enhanced strength relative to unalloyed $\mathrm{Cu}$. The flyer-plate velocity was determined by using pins located in four positions equally spaced around the lateral momentum trap [Figure 2(a)]. 
The shock pressures were determined using the flyer plate velocity in conjunction with the $\mathrm{U}_{\mathrm{s}}$ vs. $\mathrm{U}_{\mathrm{p}}$ linear relationship. The copper samples were shocked at $30 \mathrm{GPa}$ and $57 \mathrm{GPa}$, from an initial temperature of $88 \mathrm{~K}$ obtained by cooling the assembly with liquid nitrogen. The surface of the monocrystals was protected from direct impact by electrodeposition of $\mathrm{Cu}$ cover plate material, followed by finish machining to a high tolerance (prior to electrodeposition, the $\mathrm{Cu}$ samples were protected with a release agent).

The laser shock experiments were primarily carried out at the OMEGA Laser Facility at University of Rochester's Laboratory for Laser Energetics (LLE). Preliminary and follow-up experiments were performed using the JANUS Laser at Lawrence Livermore National Laboratory (LLNL). The input laser energies used in the experiments are, for [001]: $40 \mathrm{~J}, 70 \mathrm{~J}, 205 \mathrm{~J}$, and $300 \mathrm{~J}$. For [221] one experiment at $300 \mathrm{~J}$ energy was carried out. The energies can be translated into pressures using Lindl's equation [26]:

$$
P=40\left(\frac{I_{15}}{\lambda}\right)^{2 / 3}
$$

Where $\mathrm{P}$ is pressure (MBar), $\mathrm{I}_{15}$ is laser intensity $\left(10^{15} \mathrm{w} / \mathrm{cm}^{2}\right)$, and $\lambda$ is wavelength in micrometers. The laser spot size was on the order of $2.5 \mathrm{~mm}$ to $3 \mathrm{~mm}$, depending on the size of the sample and the pulse durations were typically $2.5 \mathrm{~ns}$ with a small number of experiments occurring at $6 \mathrm{~ns}$. This experimental setup provided energy densities on the order of $50 \mathrm{MJ} / \mathrm{m}^{2}$. For the recovery experiments, single crystals of $\mathrm{Cu}$ with an [100] orientation were obtained from Goodfellow in the form of disks with 2.0-3.0 mm diameter and $1 \mathrm{~mm}$ thickness. They were mounted into foam-filled recovery tubes shown in Figure 2 (c). Foam with a density of $50 \mathrm{mg} / \mathrm{cm}^{3}$ was used to decelerate the samples for recovery. The shock amplitude at the surface of the $\mathrm{Cu}$ crystal can be obtained from the laser energy and the computed values (using hydrocode calculations). In some experiments, a $\mathrm{CH}$ plastic layer was used as an ablator. This resulted in an impedance mismatch at the $\mathrm{CH} / \mathrm{Cu}$ interface, which enhanced the shock pressure in the copper specimen. Due to the short duration of the shock created by the 3 ns laser pulse, the decay in the specimen is very rapid. This decay is calculated by a hydrodynamics code. 


\section{Experimental Results}

\subsection{Deformation microstructures for plate impact and laser shock at 30-40 GPa}

For the $<100>$ orientation, the microstructures are characterized by stacking faults, as shown in Figure 3. This is known and has been established by Murr [27, 28], among others. The average spacing between stacking faults is between 230 and $450 \mathrm{~nm}$ for the laser shocked samples and between 180 and 220 for the plate-impact shocked sample. Figs. 3 (a) and (b) show the stacking fault patterns similar to the ones observed by Murr [29] for the $30 \mathrm{GPa}$ plate-impact shocked samples. It shows the two sets of stacking faults as the traces of [ $\overline{2} 20]$ and [220] orientations in (001) plane when the TEM electron beam direction is $\mathrm{B}=<001>$. Fig. 3 (c) shows the stacking faults formed in $40 \mathrm{GPa}$ laser shocked samples. All four stacking fault variants viz the (111 1$) 1 / 6[112],(111) 1 / 6[\overline{1} \overline{1} 2]$,

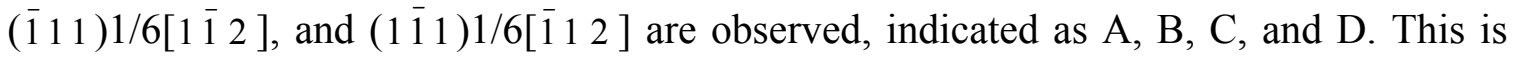
due to the fact that, for [001], they all have the same resolved shear stress. However, there is a significant difference in the activation along [ $\overline{2} 20$ ] (SF: A, B) versus [ 220 ] (SF: C, D) with the density of occurrence significantly higher in the former.

It should be noted that, in the 30 GPa plate-impact shocked $<100>$ monocrystalline copper samples, we observed isolated recrystallization as well as localized deformation bands. This was absent for the laser shocked specimens.

\subsection{Deformation microstructures for plate impact and laser shock at 55-60 GPa}

Micro-twins occur in the samples shocked at 55-60 GPa both after impact and laser shock. In plate-impacted $<100>$ monocrystalline samples, as shown in Figure 4 (a), there is only one set of micro-twins with (111 ) as their habit plane. The sizes for micro-twins vary from $80 \mathrm{~nm}$ to $180 \mathrm{~nm}$. For the laser-shocked $<100>$ samples, there are two sets of micro-twins. When imaged at $\mathrm{B}=\left[\begin{array}{lll}0 & 0 & 1\end{array}\right]$, they appear at exactly 900 to each other aligned along [ $\left.\begin{array}{lll}2 & 2 & 0\end{array}\right]$ (set A) and $\left[\begin{array}{lll}2 & 2 & 0\end{array}\right]$ (set B) directions, respectively, and they are present roughly in same proportion (not shown here). Set A exhibits a wide range of lengths, from as small as $70 \mathrm{~nm}$ to as large as $1 \mu \mathrm{m}$; the mean value is around $125 \mathrm{~nm}$. In contrast, the set B micro-twins have a near uniform length of 70nm. Fig. 4 (b) shows set

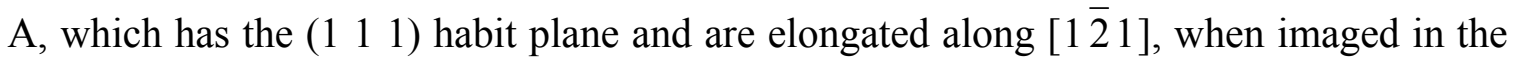


edge orientation at $\mathrm{B}$ close to $[\overline{1} 01]$. It should be noted that the deformation microstructure was not uniform around the perforation in either of the two kinds of samples.

For the $57 \mathrm{GPa}$ plate-impact shocked samples, there are deformation bands, slip bands, recrystallized regions and dislocation tangles in addition to micro-twins. Figure 5 (a) shows an overview TEM near the back surface of the specimen. A deformation band with approximately $1.5 \mu \mathrm{m}$ width is seen traversing the specimen. In comparison with the slip/stacking faults bands around it, this deformation band is larger and breaks them up. Selected area diffraction identifies the vertical slip bands as (111). It appears that the horizontal slip bands were activated earlier than the vertical bands, because the horizontal bands seem to be interrupted by the vertical ones. One can also see that the appearance of these stacking faults is different from the ones shown in Fig. 3. There is evidence for recovery processes within them. These broad bands are absent after laser shock because of the much smaller time. Indeed, the shock velocity is approximately $5.6 \mathrm{~mm} / \mu \mathrm{s}$. A duration of $1.4 \mu$ s can generate heterogeneities extending over a few $\mathrm{mm}$. On the other hand, laser shock, with duration of only $2 \mathrm{~ns}$, is much more restricted in its ability to generate inhomogeneities. These would be a few micrometers long, and their thickness would be much reduced. In Fig. 5 (b), we can see regular dislocation cell arrays. Between two arrays, dislocation tangles and in some places the density of dislocation is very high. The The dislocation density is lower in the second thin foil along the shock direction. Extended arrays of dislocation arrays/stacking faults can be seen. These are quite unlike the cells observed by other investigators (e.g., Johari and Thomas [30]). Mughrabi and Ungar [31] found some dislocation cell structures very similar to our observation. Gray and Follansbee [32] believe that increasing peak pressure or pulse duration decreased the observed dislocation cell size and increased the yield strength.

However, the major difference between the laser shocked samples and plate-impact shocked samples in 55-60 GPa regime is the presence of fully recrystallized regions in the latter. The recrystallized grains in the $57 \mathrm{GPa}$ plate-impact shocked $<100>$ sample are similar to those for the $30 \mathrm{GPa}$ plate-impact, but much more extensive.

For the 55-60 GPa laser shocked samples, there are some laths away from the center (Figure 6), while micro-twins situated closer to the center. Unlike the micro-twins, the 
laths are elongated close to $<220>$. In some regions they are aligned along [ $\overline{2} 20$ ] and in other along [ $\left.\begin{array}{lll}2 & 2 & 0\end{array}\right]$. The intermediate area shows laths misoriented from [ 220$]$. Given the curvature of the laths it is unlikely that they conform to any single habit plane. Nonetheless, the projected width of the lath interface shows a minimum at $\mathrm{B}=[001]$, and a maximum at either $\left[\begin{array}{lll}1 & 0 & 1\end{array}\right]$, or $\left[\begin{array}{ll}1 & 01\end{array}\right]$, where the respective $\{111\}$ are in the edge orientation. The lath interface plane is parallel to [001] and therefore uniquely different from micro-twins. In fact, on rare occasions we observe laths containing some microtwins.

Schneider [25] explained the features revealed by Figure 6 for laser shocked samples. These features are believed in total agreement with the "wavy sub-grains" observed after high-pressure shock compression by Murr [29] (in particular, note similarities with Figs. 34 and 35). This structure is also analogous to the one observed by Gray [33] in specimens where the residual strain was high. Thus, it is suggested that the substructures are due to thermal recovery of the shock-induced microstructure. The orientation close to $\{111\}$ of the boundaries is a residue of the original twin boundaries. This microstructure represents the recovered state of a heavily twinned and dislocated structure. While for the

plate-impact shocked samples at the same pressure, the heavily dislocated structures may indicate that the there is not as much as recovery in laser shocked samples.

TEM on impacted and laser shocked $<221>$ orientation was also conducted. Large recrystallized grains were observed by both TEM and ECC [34], as shown in Figures 7 (a) and (b). Annealing twins grow in the recrystallized grains, whereas in laser shocked $<221>$ monocrystalline copper samples, only dislocations were seen.

\section{Analysis}

\subsection{Heat Extraction from shocked specimens}

Laser and plate-impact shocks have different wave shapes and duration times: $2 \mathrm{~ns}$ for the laser experiments and $1-2 \mu$ s for flyer plate experiments. It is important to notice these here because they may bring much different effects on the heat generated during shock and the heat transfers after that. 
When a shock wave compresses the samples, the shock amplitude attenuates along the propagation direction. We can see from Fig. 1 (a) that the top of the shock travels with the velocity of $C+U_{p}$. The front of the shock wave travels with the velocity of $U_{s}$. The bottom of the part that is beyond the peak pressure travels with a velocity of $\mathrm{C}_{0}$. For the plate-impact shock wave, the distance that the peak pressure is maintained, S, can be calculated to a first approximation, by:

$$
\begin{gathered}
\mathrm{S}=\frac{U_{s}^{2} t_{p}}{U_{p}+C-U_{s}} \\
\mathrm{U}_{\mathrm{s}}=\mathrm{C}_{0}+\mathrm{S}_{1} \mathrm{U}_{\mathrm{p}}
\end{gathered}
$$

The parameters for copper are:

$\mathrm{S}=1.489 \mathrm{~km} / \mathrm{s}$; When $\mathrm{P}=57 \mathrm{GPa}, \mathrm{U}_{\mathrm{s} 1}=5.64 \mathrm{~km} / \mathrm{s}, \mathrm{U}_{\mathrm{p} 1}=1.142 \mathrm{~km} / \mathrm{s}, \mathrm{C}_{1}=5.846 \mathrm{~km} / \mathrm{s}$; When $\mathrm{P}=30 \mathrm{GPa}, \mathrm{U}_{\mathrm{s} 1}=4.95 \mathrm{~km} / \mathrm{s}, \mathrm{U}_{\mathrm{p} 1}=0.679 \mathrm{~km} / \mathrm{s}, \mathrm{C}_{1}=5.131 \mathrm{~km} / \mathrm{s}$.

We can thus obtain the progress of the shock pulse through the sample and its decay, shown in Figure 8(a) for both $30 \mathrm{GPa}$ and $57 \mathrm{GPa}$. Fig. 8 (b) represents the shock pressure decay for laser shocked samples, extracted from the laser impact energies and hydrocode calculations. It can be seen that there is an exponential decrease as a function of propagation distance. The difference between the decay rates in Fig. 8(a) and (b) is the result of the difference in pulse duration.

Based on the pressures given in Fig. 8, the shock and residual temperatures inside the samples can be calculated through Equations 4 and 5. The shock temperature $T_{s}$ is:

$$
\mathrm{T}_{\mathrm{s}}=\mathrm{T}_{0} \exp \left[\frac{\gamma_{0}}{\mathrm{~V}_{0}}\left(\mathrm{~V}_{0}-\mathrm{V}_{1}\right)\right]+\frac{\mathrm{P}\left(\mathrm{V}_{0}-\mathrm{V}_{1}\right)}{2 \mathrm{C}_{\mathrm{v}}}+\frac{\exp \left[\frac{-\gamma_{0}}{\mathrm{~V}_{0}} \mathrm{~V}_{1}\right]}{2 \mathrm{C}_{\mathrm{v}}} \int_{\mathrm{V}_{0}}^{\mathrm{V}_{1}} \mathrm{P} \exp \left(\frac{\gamma_{0}}{\mathrm{~V}_{0}} \mathrm{~V}\right)\left[2-\frac{\gamma_{0}}{\mathrm{~V}_{0}}\left(\mathrm{~V}_{0}-\mathrm{V}\right)\right] \mathrm{dV}
$$

The residual temperature $T_{\mathrm{r}}$ is:

$$
\mathrm{T}_{\mathrm{r}}=\mathrm{T}_{1} \exp \left[\frac{-\gamma_{0}}{\mathrm{~V}_{0}}\left(\mathrm{~V}_{0}-\mathrm{V}_{1}\right)\right]
$$

$\gamma_{0}$ is 1.99 for copper; $\mathrm{P}$ is the peak pressure of the shock waves; $\mathrm{V}_{1}$ is the volume of the materials at shock; $\mathrm{V}_{1}$ can be calculated the relationships between shock parameters.

$$
\mathrm{P}=\frac{\mathrm{C}_{0}^{2}\left(\mathrm{~V}_{0}-\mathrm{V}\right)}{\left[\mathrm{V}_{0}-\mathrm{S}\left(\mathrm{V}_{0}-\mathrm{V}\right)\right]^{2}}
$$




$$
\mathrm{V}=\frac{\mathrm{C}_{0}^{2}}{2 \mathrm{PS}^{2}}\left[\sqrt{1+\frac{4 \mathrm{PSV}_{0}}{\mathrm{C}_{0}^{2}}}+\frac{2 \mathrm{~S}(\mathrm{~S}-1) \mathrm{V}_{0} \mathrm{P}}{\mathrm{C}_{0}^{2}}-1\right] \quad\left(\mathrm{m}^{3} / \mathrm{kg}\right)
$$

$\mathrm{C}_{0}$ and $\mathrm{S}$ are the parameters used to describe the relationship between shock velocity $\mathrm{U}_{\mathrm{s}}$ and particle velocity $\mathrm{U}_{\mathrm{p}}$ :

$$
U=C_{0}+S_{1} U_{p}+S_{2} U_{p}^{2}+\cdots \cdots
$$

For $\mathrm{Cu}, \mathrm{C}_{0}=3.94 \times 10^{3} \mathrm{~m} / \mathrm{s}, \mathrm{S}_{1}=1.489 \times 10^{3} \mathrm{~m} / \mathrm{s}$. We also need to consider the heat capacity $\mathrm{C}_{\mathrm{v}}$ (the specific heat at constant volume). The values of specific heat at constant pressure $C_{p}$ usually are easier to measure than $C_{v}$. $C_{v}$ can be evaluated solely from $C_{p}$ and P vs. T data.

$$
\begin{aligned}
& C_{v}=T\left(\frac{\partial S}{\partial T}\right)_{v} \\
& C_{p}=T\left(\frac{\partial S}{\partial T}\right)_{p} \\
& \mathrm{C}_{\mathrm{p}}-\mathrm{C}_{\mathrm{v}}=\frac{v \mathrm{~T} \beta^{2}}{\mathrm{~K}_{\mathrm{T}}}
\end{aligned}
$$

Where $\beta$ is the volumetric expansion coefficient and $\mathrm{K}_{\mathrm{T}}$ is the isothermal coefficient of compressibility.

Using Eqns. 2-11, the residual temperatures throughout the samples immediately after shocking (no heat transfer) can be calculated. The calculated values are shown in Figure 9.

The second step is to calculate the heat transfer after shock. The following assumptions are made: 1) Conduction is one-dimensional; 2) The copper sample is a semi-infinite medium; 3) The copper sample has uniform and constant thermal properties; 4) The temperature profiles at time $t=0$ are shown in Fig. 9 (no interaction between the traveling wave and heat transfer). Assumption 4 is justified by the fact that the thermal transport velocity is negligible in comparison with the wave propagation velocity.

$\begin{aligned} & \text { Rate of heat conduction } \\ & \text { into control volume }\end{aligned}=\begin{aligned} & \text { Rate of heat conduction } \\ & \text { out of control volume }\end{aligned}+\begin{aligned} & \text { Rate of energy storage } \\ & \text { inside control volume }\end{aligned}$

Dividing the samples into small elements and calculating the heat transfer separately [35]: 


$$
\mathrm{T}_{\mathrm{i}, \text { new }}=\mathrm{T}_{\mathrm{i}, \text { old }}+\frac{\Delta t k}{\rho c \Delta^{2} x}\left(\mathrm{~T}_{\mathrm{i}+1, \text { new }}-2 \mathrm{~T}_{\mathrm{i}, \mathrm{m}}+\mathrm{T}_{\mathrm{i}-1, \mathrm{~m}}\right) \quad \text { for }(1 \leq i \leq N)
$$

Consider specified flux boundary conditions as:

$$
\begin{gathered}
\mathrm{T}_{1, \text { new }}=\mathrm{T}_{1, \text { old }}+\left(\mathrm{T}_{2, \text { new }}-\mathrm{T}_{1, \mathrm{~m}}\right) \\
\mathrm{T}_{\mathrm{N} \text {, new }}=\mathrm{T}_{\mathrm{N} \text {, old }}+\left(\mathrm{T}_{\mathrm{N}-1, \text { new }}-\mathrm{T}_{\mathrm{N}, \mathrm{m}}\right)
\end{gathered}
$$

For copper, the parameters are: $\mathrm{K}$ (thermal conductivity) equals to $401 \mathrm{w} / \mathrm{m}-\mathrm{K}$; CSpecific heat, $C_{300 K}=364 \mathrm{~J} / \mathrm{Kg}-\mathrm{K} ; \rho$-density, $\rho_{300 \mathrm{k}}=8920 \mathrm{Kg} / \mathrm{m}^{3} ;$ D-thermal diffusivity, $\mathrm{D}=\frac{k}{\rho C_{p}}$.

Figures 10 and 11 show the change of temperature with time for $30 \mathrm{GPa}$ and $57 \mathrm{GPa}$ plate impacts. For $30 \mathrm{GPa}$, the maximum temperature (at surface) changes from approximately $160 \mathrm{~K}$ to $100 \mathrm{~K}$ during a period of $1000 \mathrm{~s}$. For $57 \mathrm{GPa}$, the maximum temperature changes from approximately $360 \mathrm{~K}$ to $140 \mathrm{~K}$ during this same time period (1000 s). This period of time should be sufficient to induce some microstructural changes inside the samples. Figure 12 shows the temperature changes at a fixed section for a distance $\mathrm{L}=5 \mathrm{~mm}$ from the impact interface. One can see that in the front part of the sample (within $5 \mathrm{~mm}$ ), the temperature remains above $160 \mathrm{~K}$ (for the $57 \mathrm{GPa}$ shock), and above $100 \mathrm{~K}$ (for the $30 \mathrm{GPa}$ shock) for $1000 \mathrm{~s}$.

For laser shock, the region which is affected by the temperature rise is much shorter (up to $1 \mathrm{~mm}$, as shown in Fig. 9). The temperature excursions in laser shocked samples are shown in Figure 13 and 14. These results were calculated by the same procedure as the plate impact samples (Figs. 11 and 12). By comparing the temperature changes in those two experiments, it is easy to notice that, first, the laser shock affected distance is much shorter and second, the temperature drop is much more rapid for laser shock.

The temperature essentially decays to a level below $100 \mathrm{~K}$ in a time on the order of $0.2 \mathrm{~s}$. These results explain why, although the peak pressures of laser shock are much higher than those of impact (Fig. 9), resulting in higher residual temperatures, and the post-shock microstructures in plate impact samples show a greater effect of post shock thermal excursion. 


\subsection{Heat generation in shear localization regions}

Figure 5(a) shows a shear localization area. Other observations also confirm the presence of localized regions of concentrated shear. The plastic deformation in these regions exceeds substantially the one predicted from uniaxial strain, and one can expect local fluctuations in temperature. Indeed, the temperature rise in the shear localization areas can be calculated from the constitutive response of copper. This deformationinduced temperature rise was considered earlier by Lassila et al. [24]. It is expressed as:

$$
\Delta \mathrm{T}_{\mathrm{d}}=\frac{\beta}{\rho \mathrm{C}_{\mathrm{p}}} \int_{\varepsilon_{0}}^{\varepsilon_{1}} \sigma \mathrm{d} \varepsilon
$$

where $\rho$ is the density, $C_{p}$ is the heat capacity, and $\beta$ is the Taylor factor. For most metals, $\beta$ is usually taken as $0.9-1.0$. The strength of the material $\sigma$ has to be estimated under specified conditions in different cases. We use the Johnson-Cook [36] equation:

$$
\begin{gathered}
\sigma=\left(\sigma_{0}+\mathrm{B} \varepsilon^{\mathrm{n}}\right)\left(1+\mathrm{C} \log \frac{\dot{\varepsilon}}{\varepsilon_{0}}\right)\left[1-\left(\frac{\mathrm{T}-\mathrm{T}_{\mathrm{r}}}{\mathrm{T}_{\mathrm{m}}-\mathrm{T}_{\mathrm{r}}}\right)^{\mathrm{m}}\right] \\
\mathrm{T}^{*}=\frac{\mathrm{T}-\mathrm{T}_{\mathrm{r}}}{\mathrm{T}_{\mathrm{m}}-\mathrm{T}_{\mathrm{r}}}
\end{gathered}
$$

The temperature change due to the plastic deformation is expressed as:

$$
\mathrm{T}^{*}=1-\exp \left[\frac{-0.9\left(1+\mathrm{C} \log \frac{\dot{\varepsilon}}{\dot{\varepsilon}_{0}}\right)}{\rho \mathrm{C}_{\mathrm{p}}\left(\mathrm{T}_{\mathrm{m}}-\mathrm{T}_{\mathrm{r}}\right)} \times\left(\sigma_{0} \varepsilon+\frac{\mathrm{B} \varepsilon^{\mathrm{n}+1}}{\mathrm{n}+1}\right)\right]
$$

Where, $\mathrm{T}_{\mathrm{r}}=90 \mathrm{~K}, \mathrm{~T}_{\mathrm{m}}=1356 \mathrm{~K}, \mathrm{~B}=53.7 \mathrm{MPa}, \mathrm{C}=0.026, \sigma_{0}=330 \mathrm{MPa}$ (the value for shock hardened copper), $\mathrm{n}=0.56, \mathrm{~m}=1.04, \rho_{90 \mathrm{~K}}=9.05 \mathrm{~g} / \mathrm{cm}^{3}, \mathrm{C}_{\mathrm{p}, 90 \mathrm{~K}}=260 \mathrm{~J} / \mathrm{Kg}-\mathrm{K}$. Figure 15 expresses the increase in temperature as a function of strain for a hypothetical shock hardened copper specimen. There is considerable local heat generation around heavily deformed areas (such as deformation bands). These regions can act as initiation sites for post-shock recrystallization.

\section{Conclusions}

Laser and plate-impact shocked copper with two orientations ([001] and [221]) revealed similarities as well as differences, that are interpreted in terms of the shock compression and thermal excursion processes. The observations can be summarized as: 
- At lower pressures, $(30-40 \mathrm{GPa}$ range), there are profuse stacking faults in $<100>$ orientation which have traces at $90^{\circ}$ for both the laser and plate-impact experiments. The stacking-fault spacing is about the same; $200-300 \mathrm{~nm}$.

- In the 55-60 GPa range, micro-twins are observed for both laser and plateimpact shocked $<100>$ orientation.

- For $57 \mathrm{GPa}$ shock of both $<100>$ and $<221>$ orientations, there are recrystallized grains for plate impact, while no recrystallized grains appeared in laser shocked samples.

- Regions of shear localization were observed after impact shock, while they are absent after laser shock. These microshear bands have a thickness of approximately $1.5 \mu \mathrm{m}$.

The cooling times are calculated for laser and plate-impact experiments. Plate impact experiments were carried out at $88 \mathrm{~K}$ whereas laser shock experiments were conducted at ambient temperature. Nevertheless, the differences are on the order of 5000. Copper has a high thermal conductivity and provides an extraction of heat in times on the order of $0.2 \mathrm{~s}$. The cooling times for the plate-impacted samples are on the order of 1000s. The differences in residual microstructures are attributed to the much larger cooling times (x100) in the plate-impact experiments. One possible explanation for the extensive recrystallization observed is the formation of shear concentration regions (shear bands) which can raise the local temperature by hundreds of ${ }^{0} \mathrm{C}$ (depending on the plastic strain) and propitiate local conditions for recrystallization.

\section{Acknowledgement}

This research was supported by the Department of Energy through Grants DEFG0398DP00212 and DEFG0300SF2202. We thank the Shenyang National Laboratory for Materials Science for support of Bu Yang Cao during her stay in China. The plate impact experiments were conducted at the New Mexico Institute of Mining and Technology. Worked performed under the auspices of the USDOE at UC LLNL, W-7405-Eng-48. 


\section{References:}

1. J. C. M. Li, in: L. E. Murr and C. Stein (Eds.), Frontiers in Materials ScienceDistinguished Lectures, Marcel Dekker, New York, 1976, p. 527.

2. J. C. M. Li, in: Metallic Glass, ASM, Metals Park, Ohio, 1976, pp. 224-246.

3. J. C. M. Li, Proc. $4^{\text {th }}$ Int. Conf. Rapidly Quenched Metals, Sendi, Japan, 1981.

4. J. C. M. Li, Proc. Mater. Res. Soc. Symp. Rapidly Solidified Amorphous and Crystalline Alloys, Boston, 1981.

5. J. C. M. Li, Trans. TMS-AIME, 227 (1963) 75.

6. J. C. M. Li, Can. J. Phys., 45 (1967) 493-509.

7. I. Gupta and J. C. M. Li, Met. Trans., 1 (1970) 2323-2330.

8. P. Zhu, J. C. M. Li and C. T. Liu, Reaction Mechanism of Combustion Synthesis of NiAl, Mat. Sci. Eng. A, 329, (2002) 57-68

9. J. C. M. Li, in: A. R. Rosenfield, G. T. Hahn, A. L. Bement, and R. I. Jaffee (Eds.), Dislocation Dynamics, New York, McGraw-Hill, 1968, pp. 87-116.

10. C. S. Smith, Trans. AIME, 212 (1958) 574.

11. P. S. Decarli, and M. A. Meyers, in: M. A. Meyers and L. E. Murr (Eds.), Shock Waves and High-Strain-Rate Phenomena in Metals, 1981, pp. 341-373.

12. P. C. Chou and J. Carleone, J. Appl. Phys., 48 (1977) 4187-4195.

13. J. M. Walsh, J. Appl. Phys., 56 (1984) 1997-2006.

14. D. E. Grady, J. Impact Eng., 5 (1987) 285-293.

15. C. Y. Hsu, K. C. Hsu, L. E. Murr, and M. A. Meyers, in: M. A. Meyers and L. E. Murr (Eds.), Shock Waves and High-Strain-Rate Phenomena in Metals, 1981, pp. 433-452.

16. G. T. Gray III, in: Shock Induced Defects in Bulk Materials, Materials Research Society Symposia Proceedings, 499 (1998) pp. 87-98.

17. M. A. Meyers, Dynamic Behavior of Materials, John Wiley and Sons, Inc, New York, 1994.

18. K. S. Vecchio, U. Andrade, M. A. Meyers, and L. W. Meyer, in: Shock Compression of Condensed Matter, 1991, pp. 527-530.

19. B. A. Remington, G. Bazan, J. Belak, E. Bringa, M. Caturla, J. D. Colvin, M. J. Edwards, S. G. Glendinning, D. S. Ivanov, B. Kad, D. H. Kalantar, M. Kumar, B. F. Lasinski, K. T. Lorenz, J. M. Mcnaney, D. D. Meyerhofer, M. A. Meyers, S. M. Pollaine, D. Rowley, M. Schneider, J. S. Stölken, J. S. Wark, S. V. Weber, W. G. Wolfer, B. Yaakobi, L. V. Zhigilei, Metal. and Mat. Trans., 35A (2004) 25872607.

20. G. T. Gray III, in: J. R. Asay and M. Shahinpoor (Eds.), High Pressure Shock Compression of Solids, Eds Spinger-Verlag, New York, NY, 1993, pp. 187-215.

21. C. Fressengeas and A. Molinari, International Conference on Mechanical Properties of Materials at High Strain Rates, Institute of Physics Conference Series, 102 (1989) 57-64.

22. L. A. Romero, J. Appl. Phys., 65 (1989) 3006-3016.

23. J. F. Ready, Industrial Applications of Lasers, Academic Press, San Diego, 1997.

24. D. H. Lassila, T. Shen, B. Y. Cao, and M. A. Meyers, Metal. and Mat. Trans., 35A (2004) 2729-2739. 
25. M. A. Meyers, F. Gregori, B. K. Kad, M. S. Shheider, D. H. Kalantar, B. A. Remington, G. Ravichandran, T. Boehly, J. S. Wark, Acta. Metall. 51 (2003)1211-1228.

26. J. Lindl, Phys. Plasmas, 2 (1995) 3933-3982.

27. L. E. Murr and K. P. Staudhammer, Mat. Sci. Eng., 20 (1975) 35-46.

28. L. E. Murr, Scripta Met., 12 (1978) 201-206.

29. L. E. Murr, in: M. A. Meyers and L. E. Murr (Eds.), Shock Waves and HighStrain-Rate Phenomena in Metals, Plenum, NY, 1981, pp. 607-673.

30. O. Johari and G. Thomas, Acta. Metall. 12 (1964) 1153-1159.

31. H. Mughrabi, T. Ungar, W. Kienle, and M. Wilkens, Phil. Mag. A, 53 (1986) 793813.

32. G. T. Gray III and P. S. Follansbee, in: C. Y. Chiem, H. D. Kunze and L. W. Meyers (Eds.), Impact Loading and Dynamic Behavior of Materials, Informationsgells, Verlag, 1988, P. 541.

33. G. T. Gray III, in: M.A. Meyers, L. E. Murr, and K. P. Staudhammer (Eds.), Shock-Wave and High-Strain-Rate Phenomena in Materials, Dekker, NY, 1992, pp. 899-911.

34. R. Zauter, F. Petry, M. Bayerlein, C. Sommer, H.-J. Christ and H. Mughrabi, Phil. Mag. A, 66 (1992) 425-436.

35. F. Kreith and M. S. Bohn, Principles of Heat Transfer, Brooks/Cole, CA, 2000.

36. G. R. Johnson and W. H. Cook, Proc. $7^{\text {th }}$ Int. Symp. On Ballistics, ADPA, the Netherlands, 1983. 


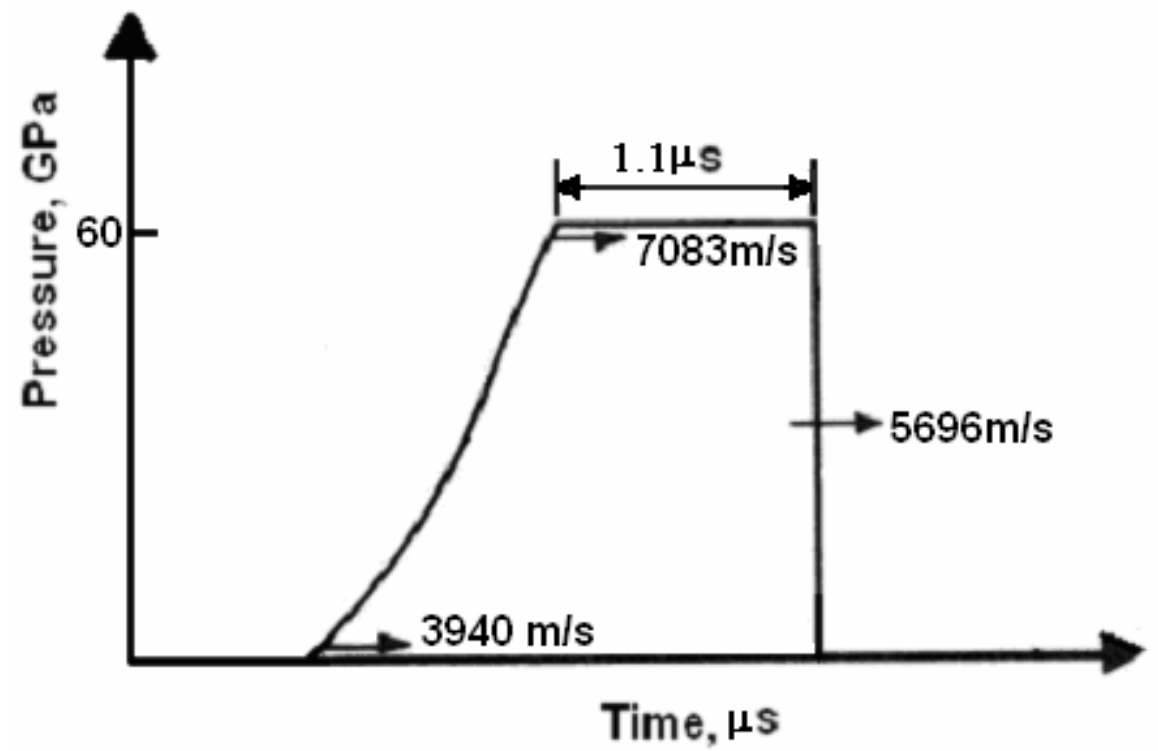

(a)

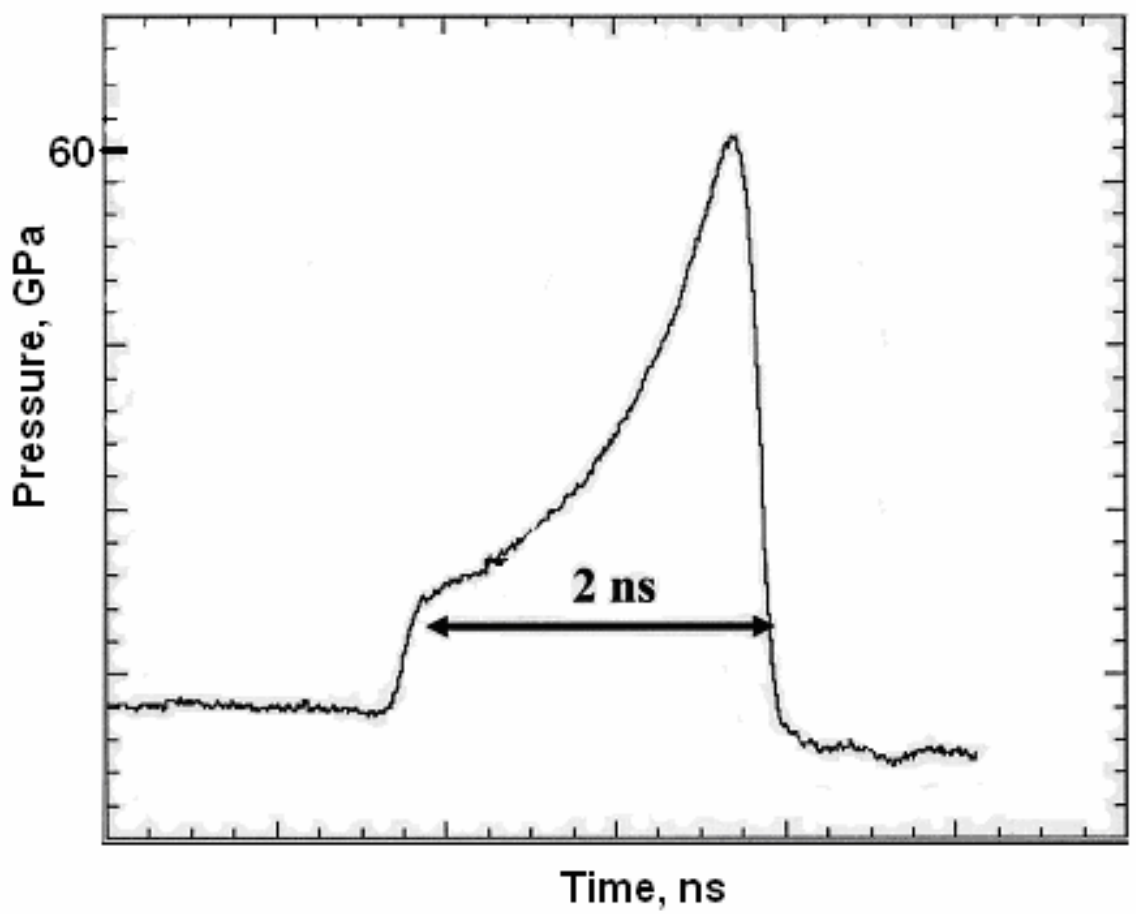

(b)

Figure 1: Shock wave configurations: (a) shock wave (trapezoidal) produced by plate impact: time duration is $1.1 \mu$ s and peak pressure is $60 \mathrm{GPa}$; (b) Pulse shape of typical laser shock experiment: time duration is 2 nanoseconds and energy is $\sim 300 \mathrm{~J}$ (equivalent to $60 \mathrm{GPa}$ ). 


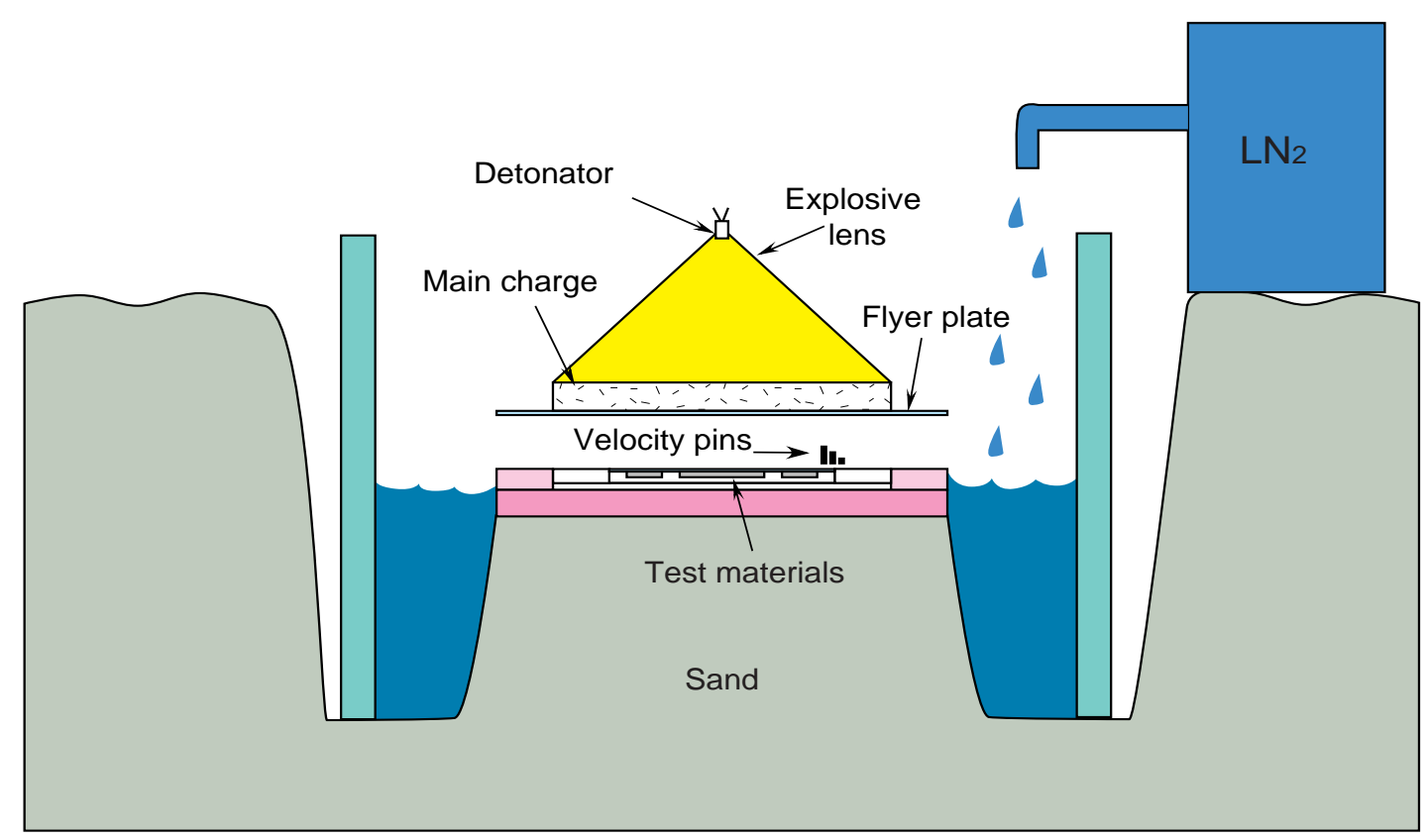

(a)

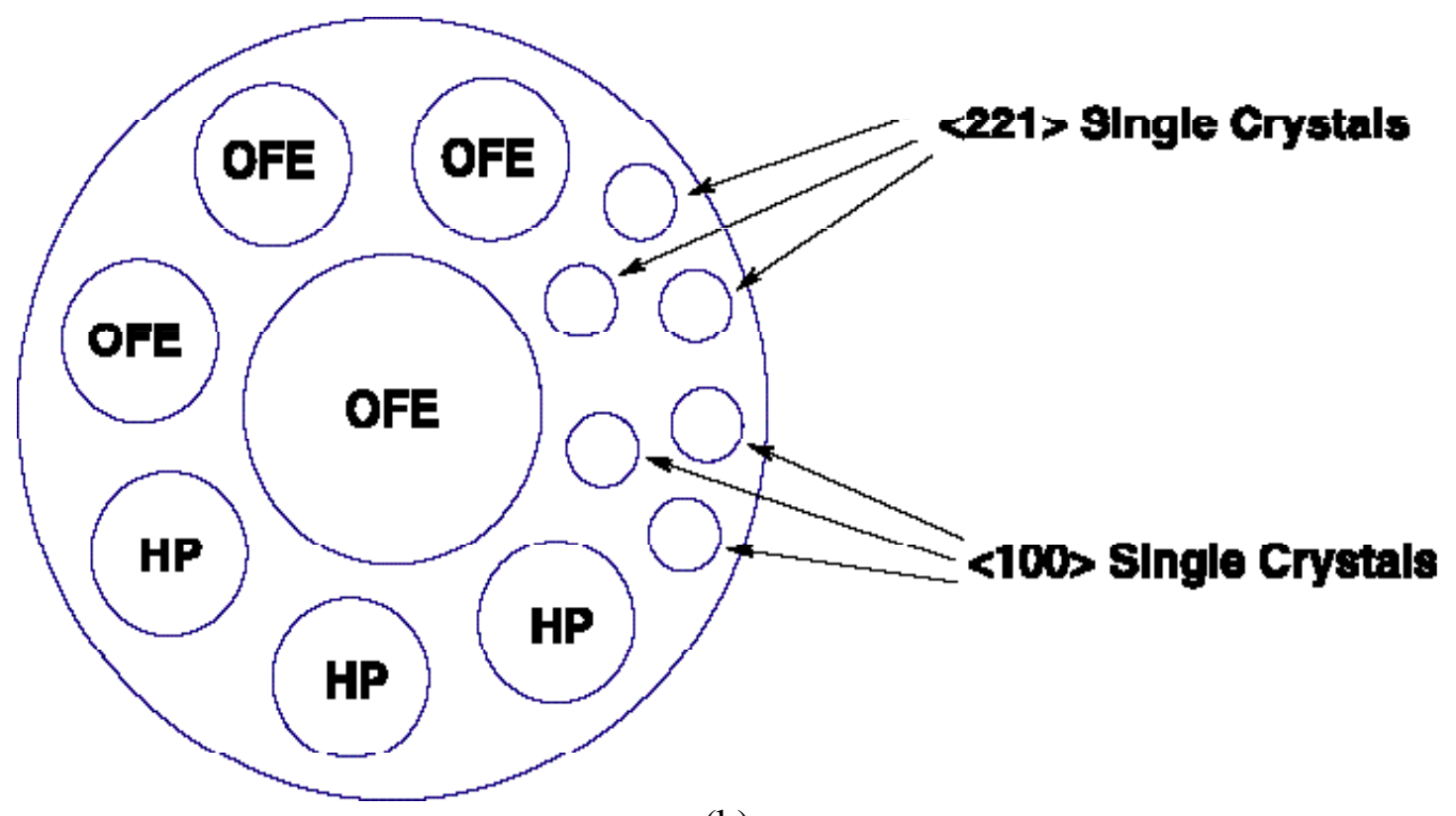

(b) 


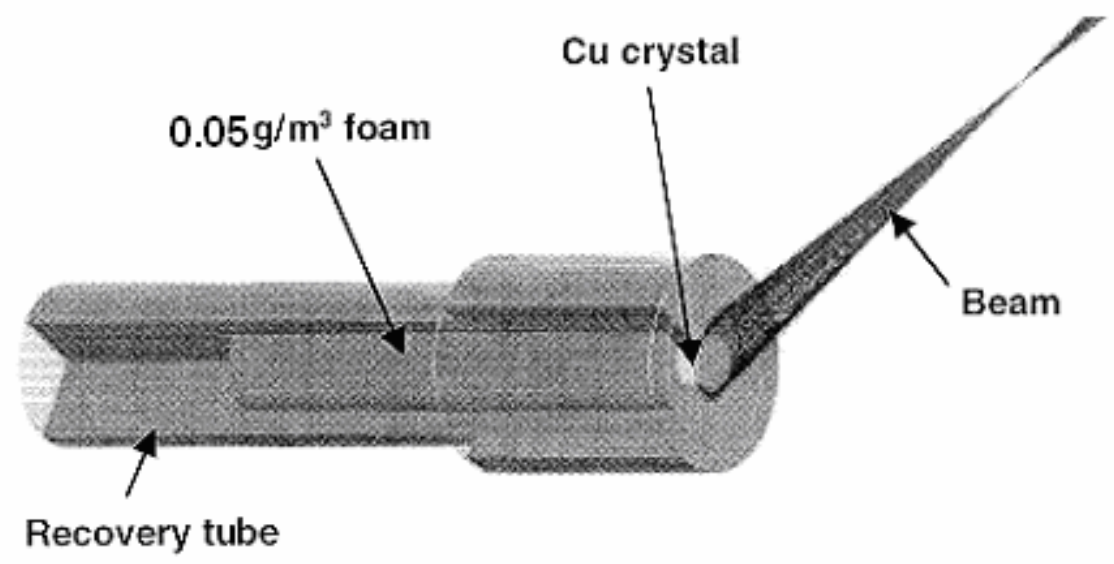

(c)

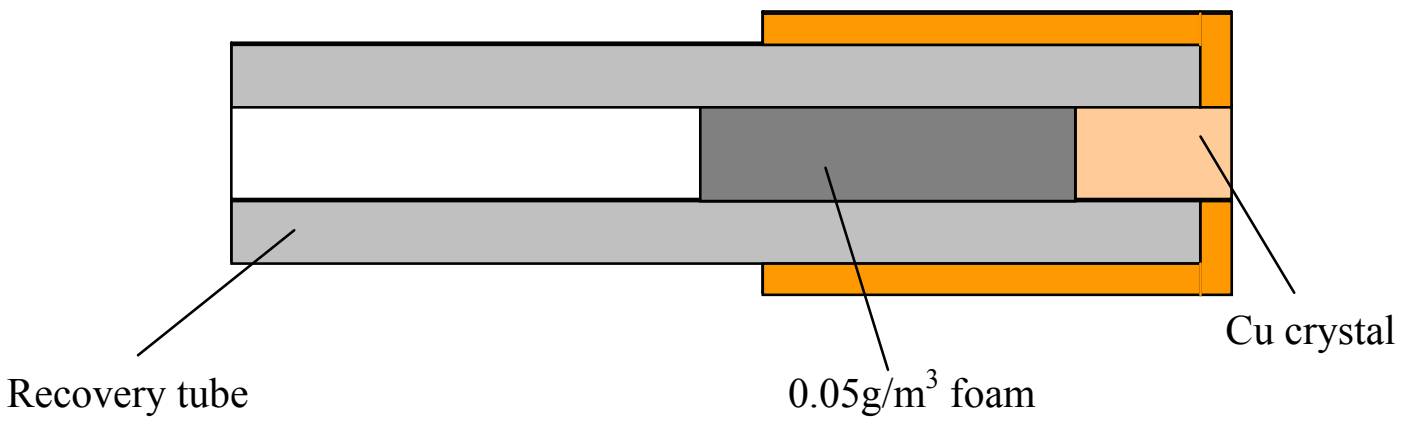

(d)

Figure 2: The experimental sets for two kinds of shock compression methods: (a) Shock recovery experiments performed by acceleration of a flyer plate by an explosive charge; (b) Anvil with OFE, HP and single crystal test samples; (c) Sample and recovery chamber for laser shock experiments; (d) the cross section of the samples and recovery chamber. 


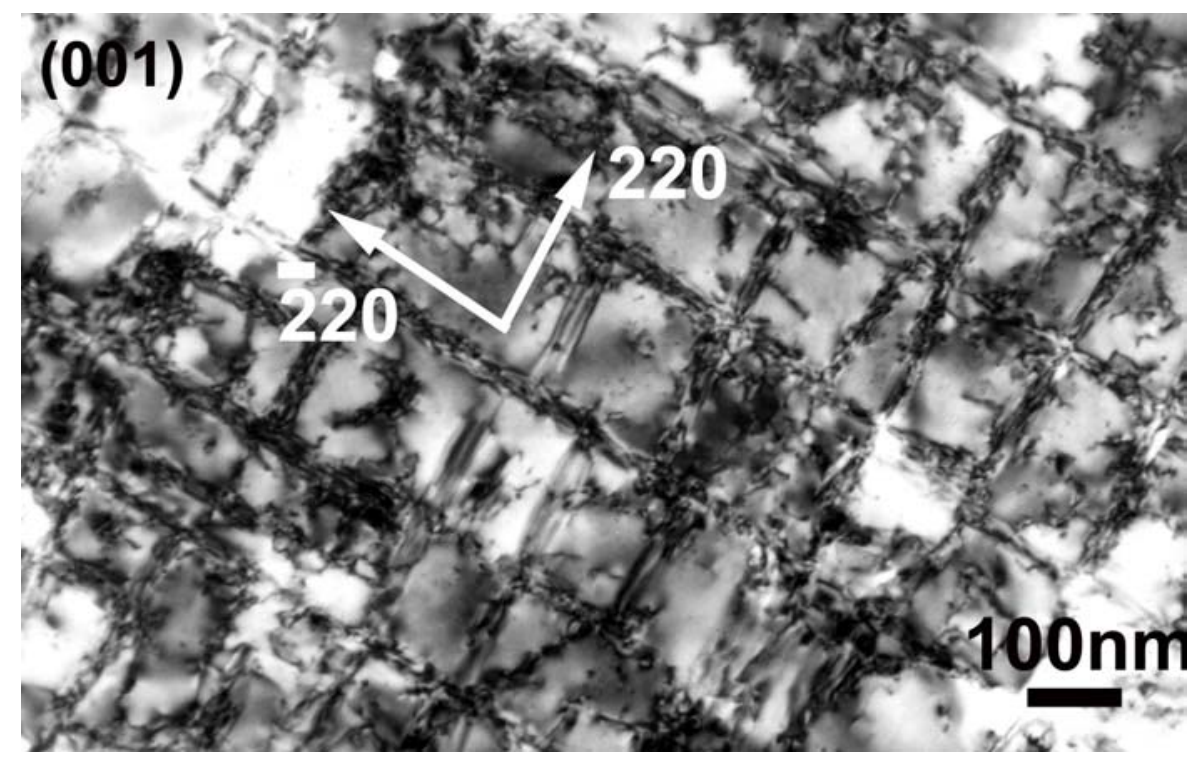

(a)

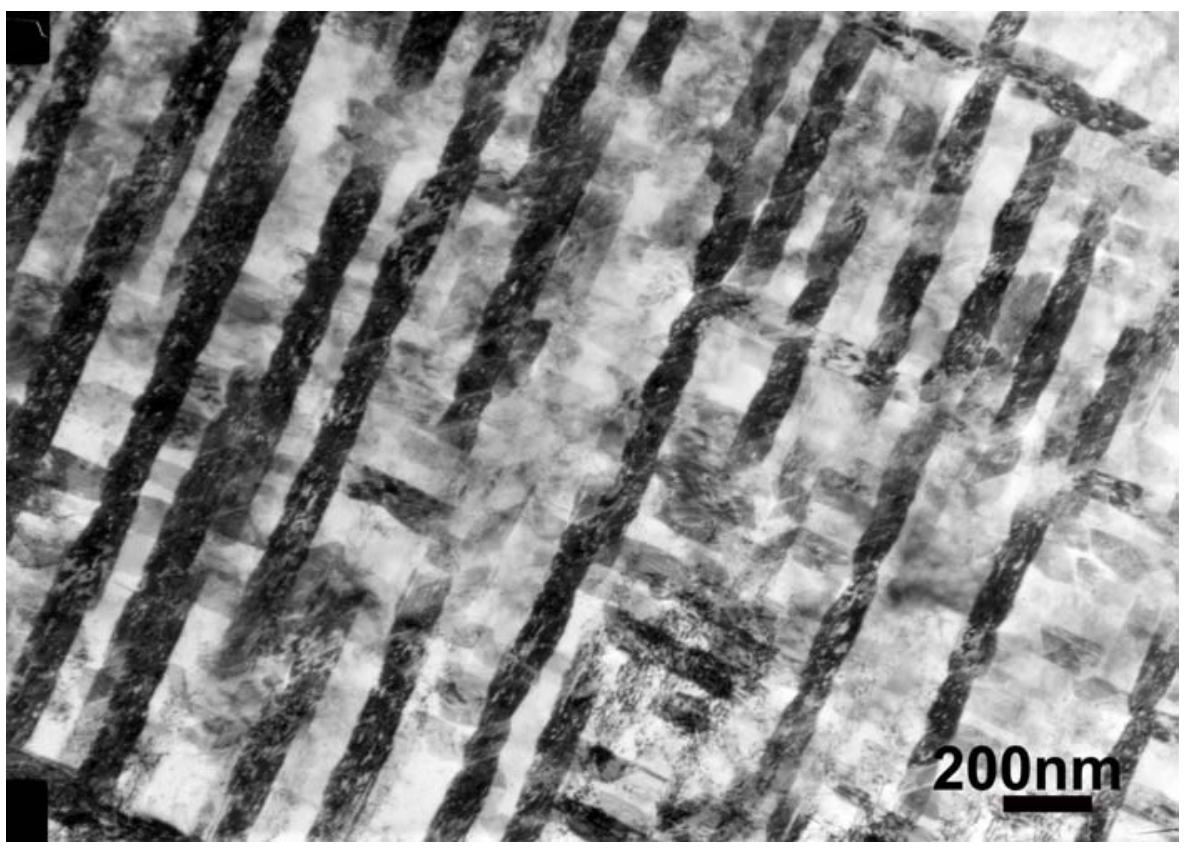

(b) 


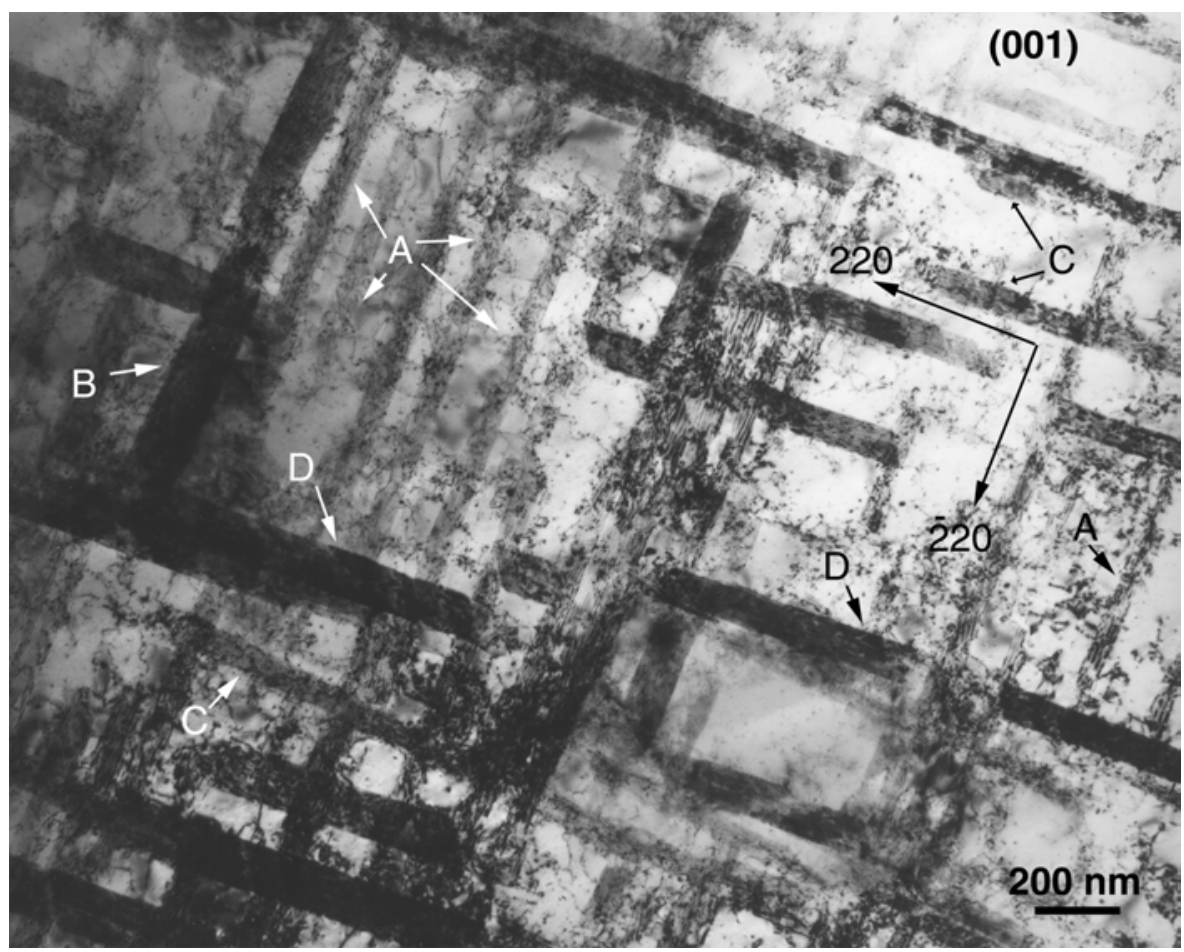

(c)

Figure 3: (a) Stacking faults in $30 \mathrm{GPa}$ impacted $<100>$ sample; (b) Stacking faults in 30 GPa impacted $<100>$ sample with large magnification; (c) $40 \mathrm{GPa}$ laser shocked $<100>$ sample: Four sets (marked as A, B, C, D) are observed. Variant A exhibits the highest density of occurrence. Energy Input $=205$ Joules, $g=200, B=[001]$. 


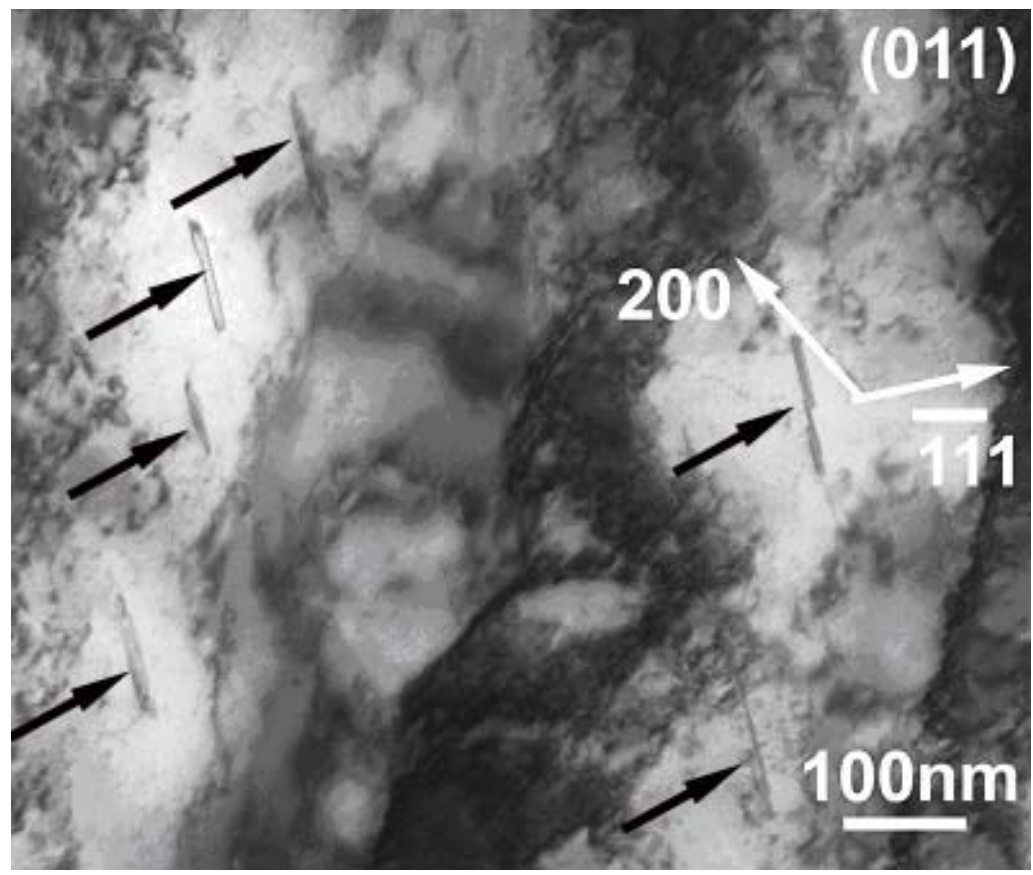

(a)

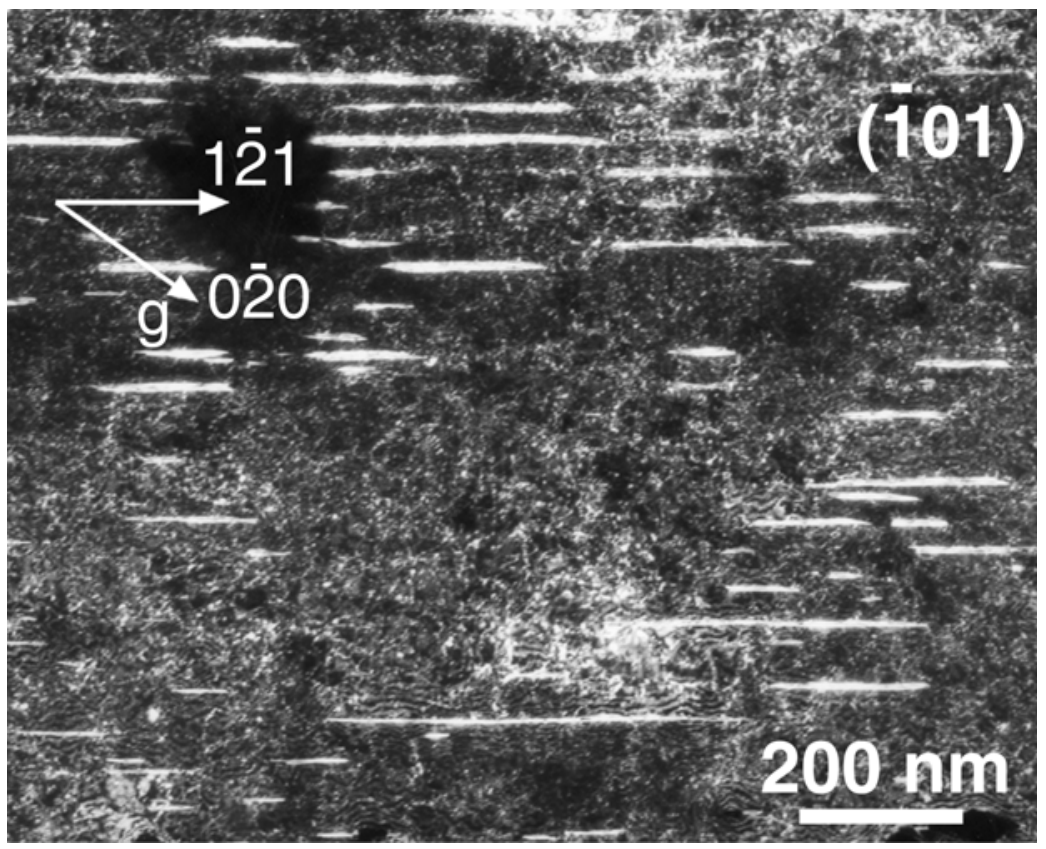

(b)

Figure 4: (a) $57 \mathrm{GPa}$ impacted sample: micro-twins with the habit plane of (111) shown at the electron beam direction of (011). (b) 55-60 GPa laser shocked sample: Micro-twins with a (111) habit plane elongated along $[1 \overline{2} 1]$ in $60 \mathrm{GPa}$ laser shocked $<100>$ sample. Energy Input $=320$ Joules, $g=0-20, B=[101]$. 


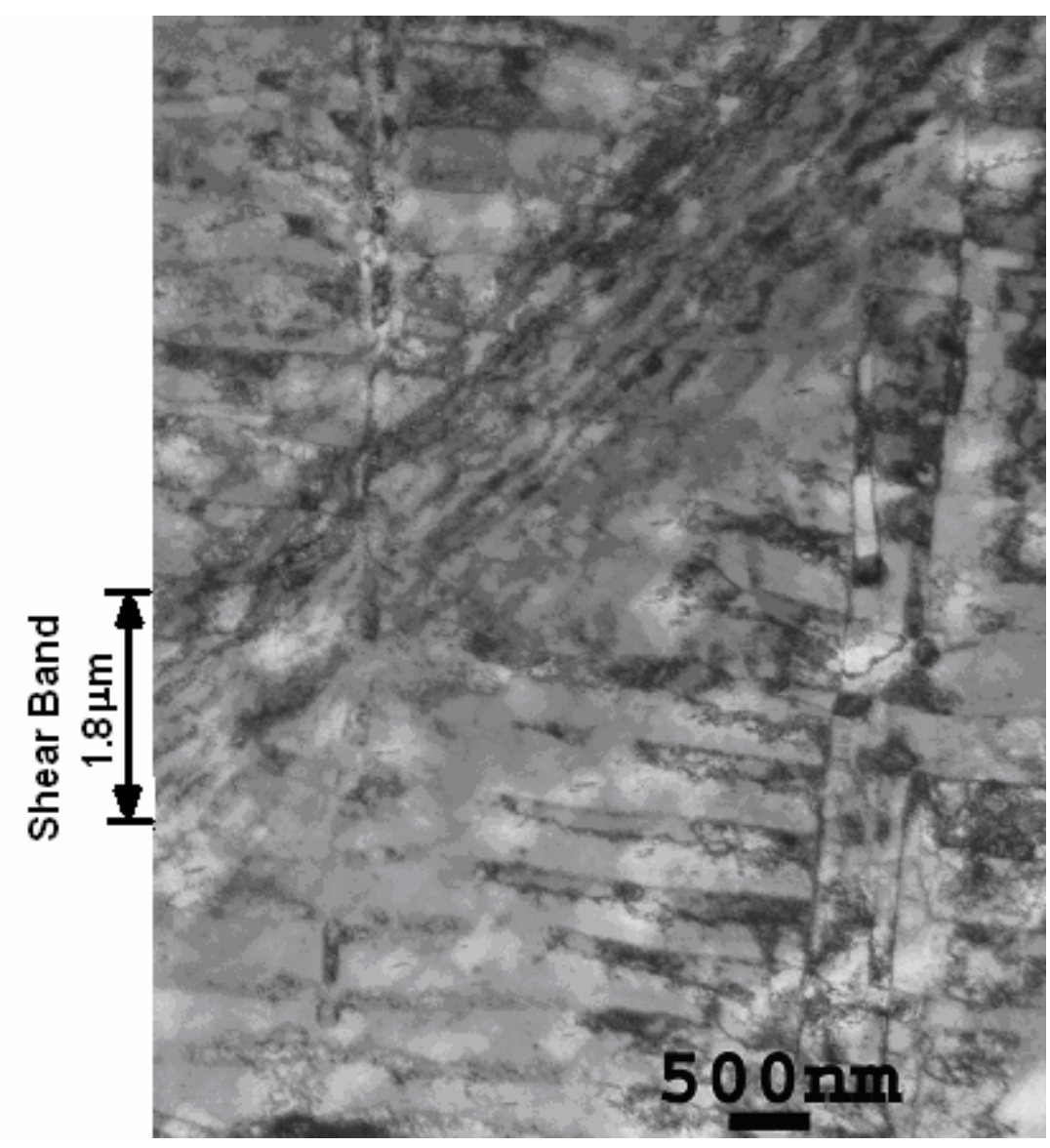

(a) 


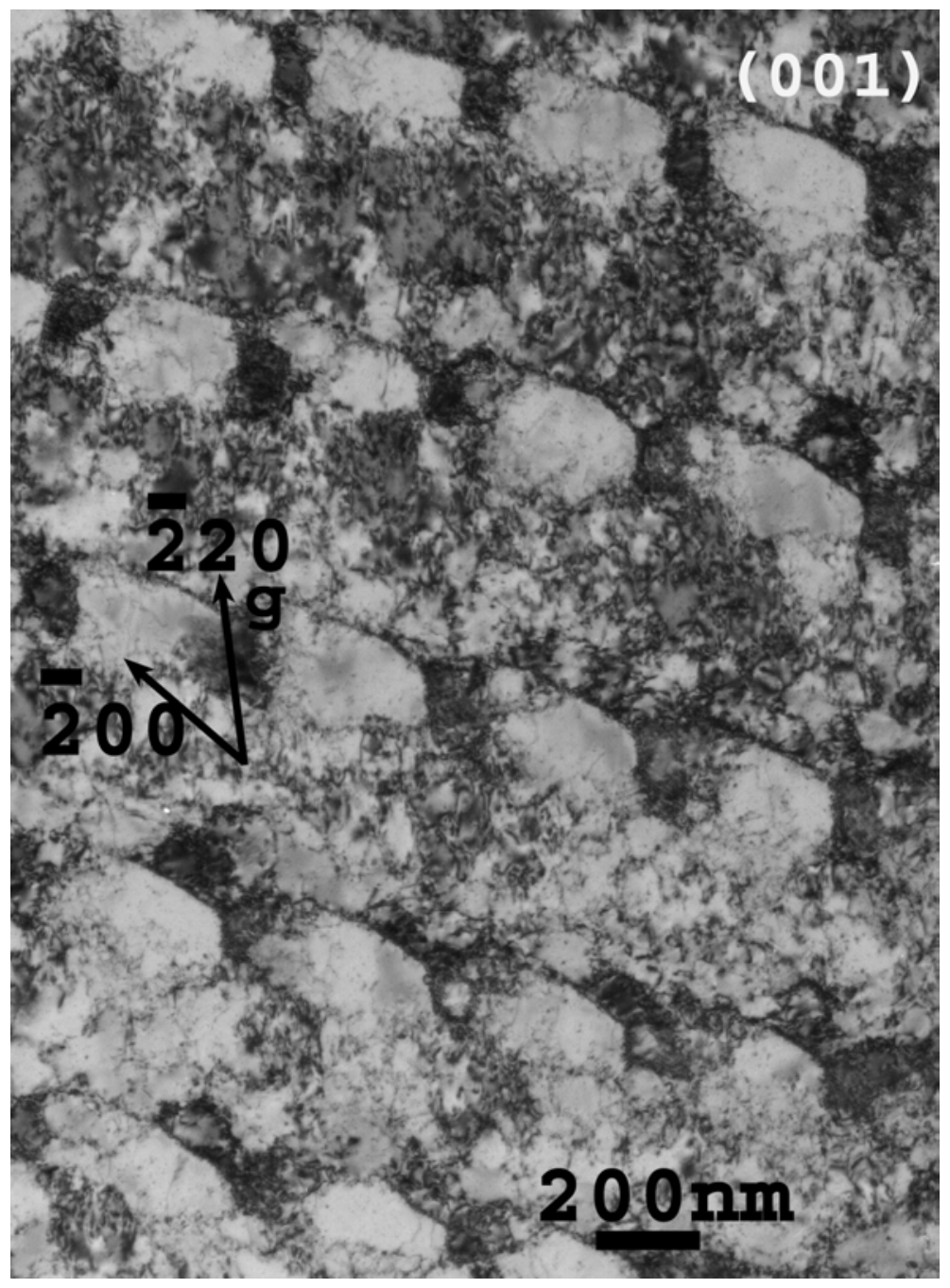

(b)

Figure 5: TEM for $57 \mathrm{GPa}$ post-shocked $<100>$ copper samples: (a) overview of the sample (x10K); (b) dislocation circles shown in the first thin foil along the shock direction. 


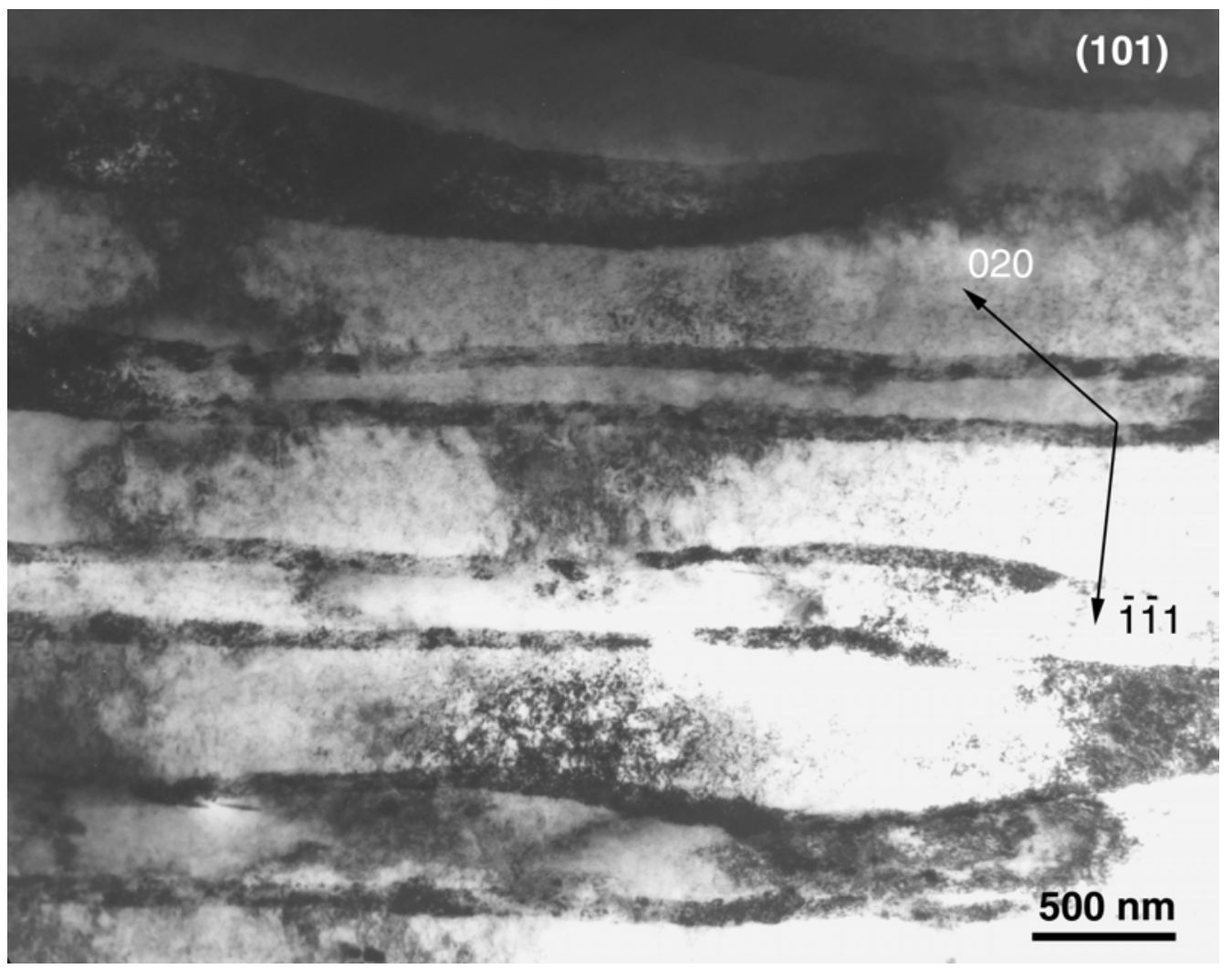

Figure 6: View of laths imaged at beam direction $\mathrm{B}=[101]$ in $55-60 \mathrm{GPa}$ laser shocked $<100>$ samples. 


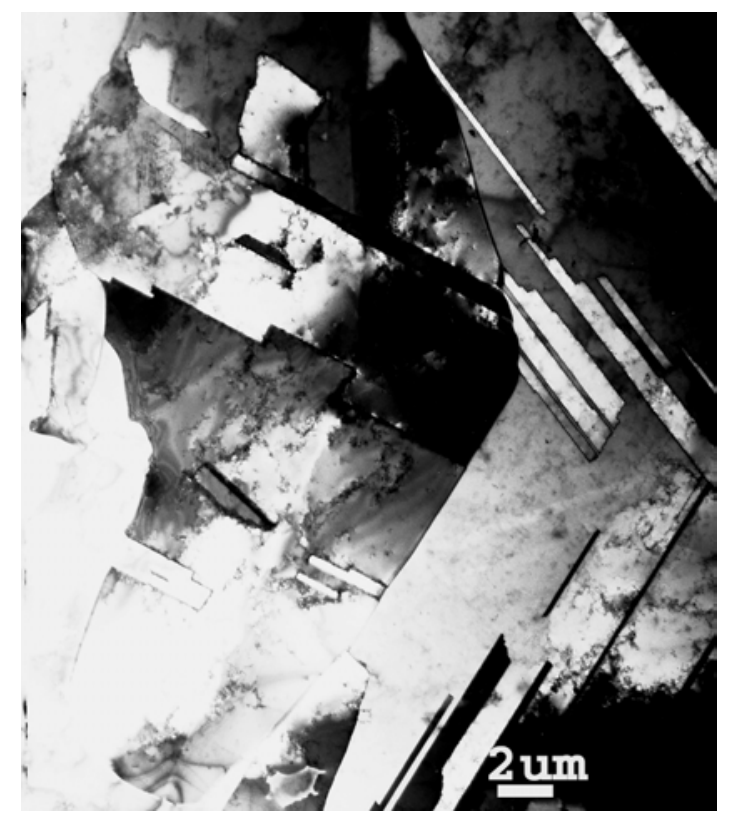

(a)

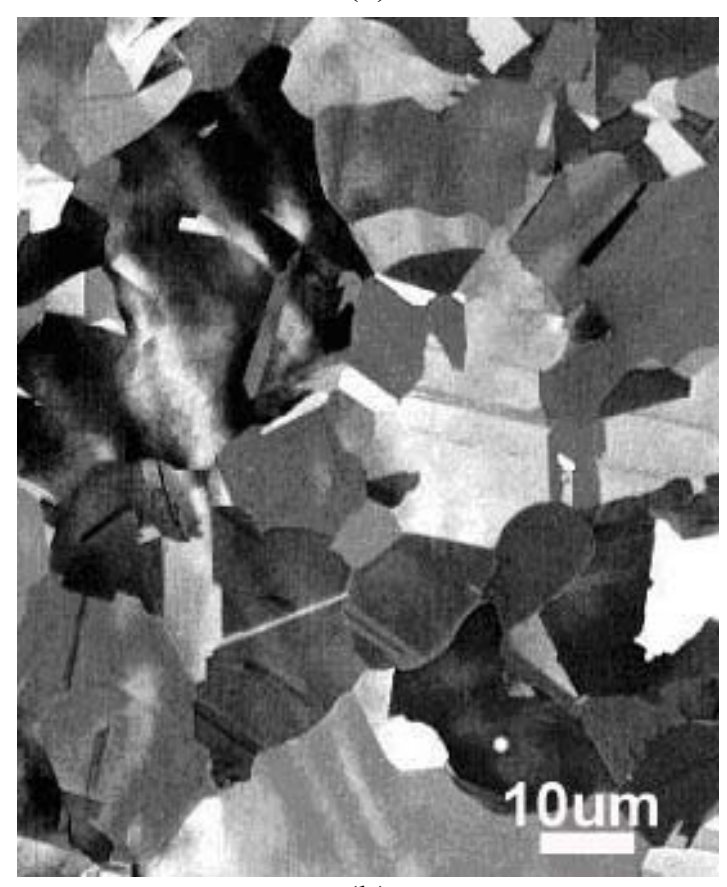

(b) 


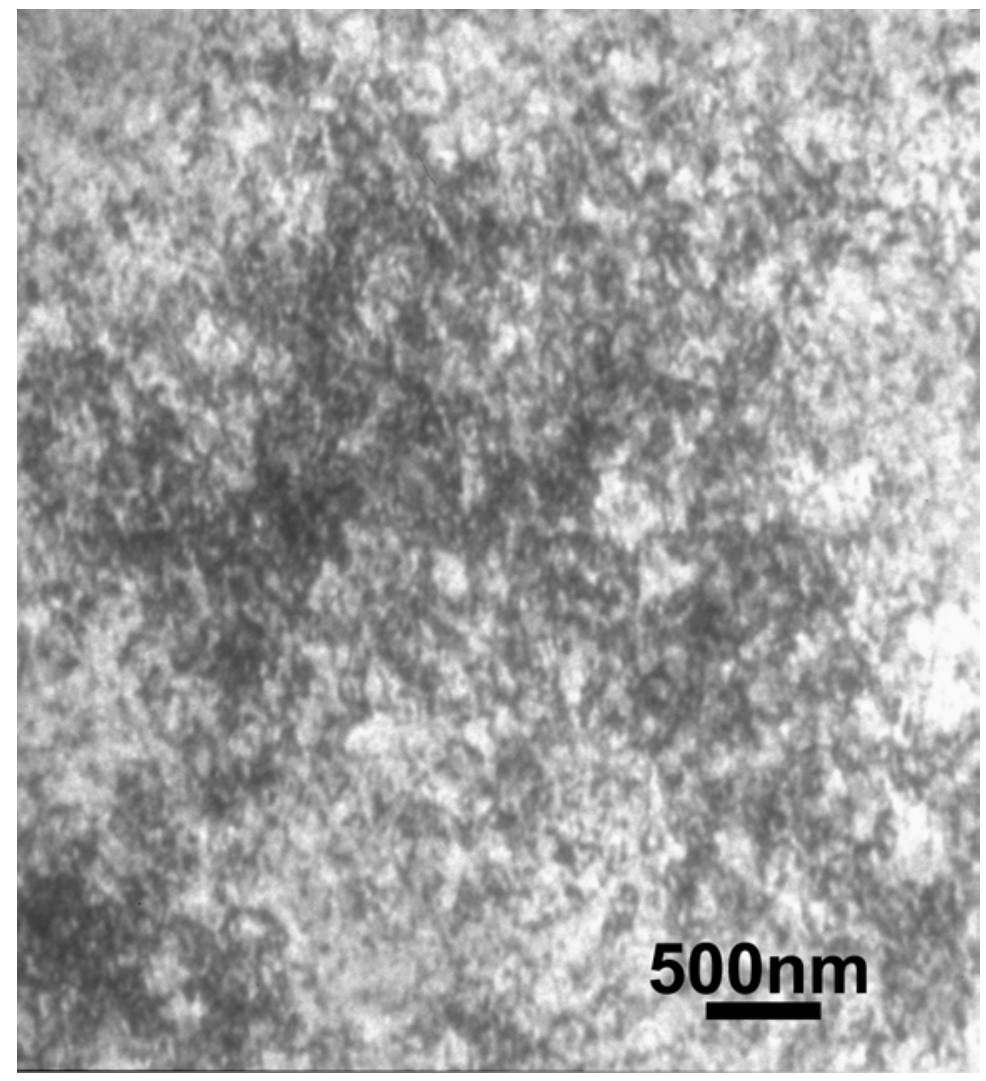

(c)

Figure 7: (a) TEM showing annealing twins and recrystallized grains in $57 \mathrm{GPa}$ impacted $<221>$ sample; (b) Recrystallized grains were observed by SEM-ECC in 57 GPa impacted $<221>$ sample; (c) Dislocations in $60 \mathrm{GPa}$ laser shocked $<221>$ samples. 


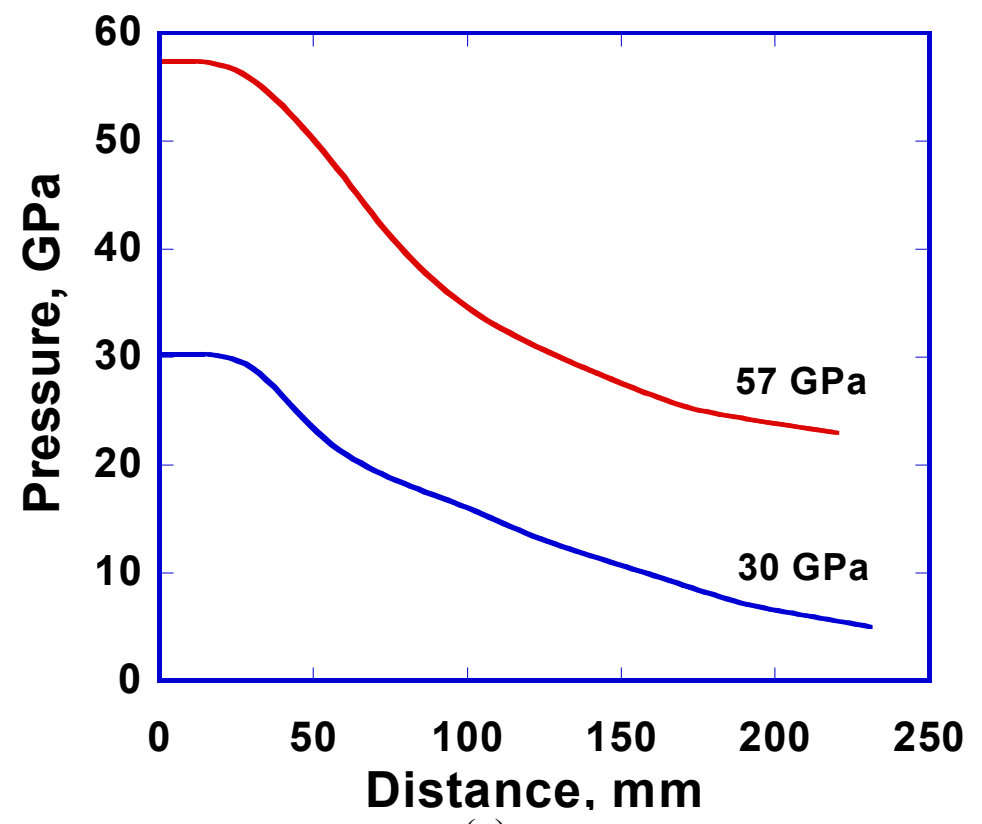

(a)

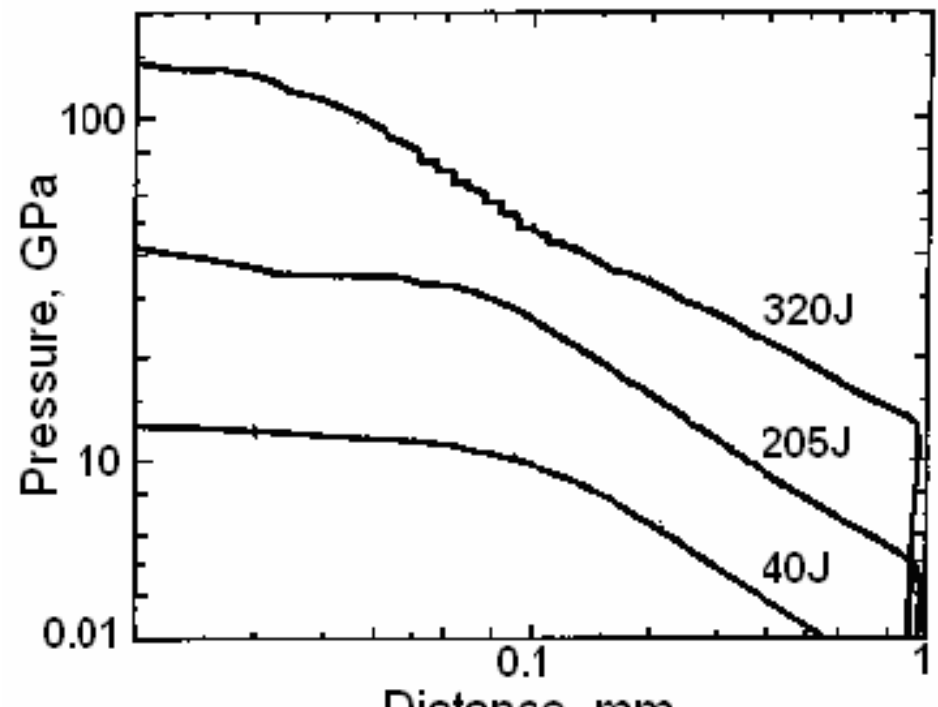

(b)

Figure 8: Pressure profiles along the samples during shock: (a) plateimpact shock; (b) laser shock. 


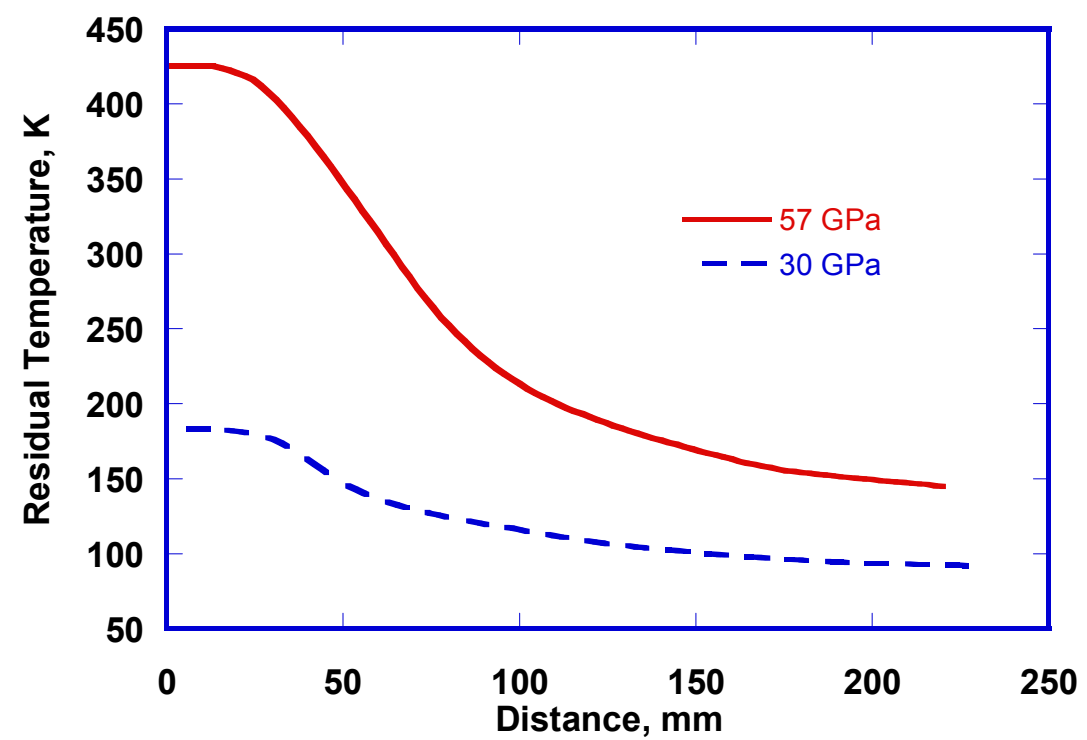

(a)

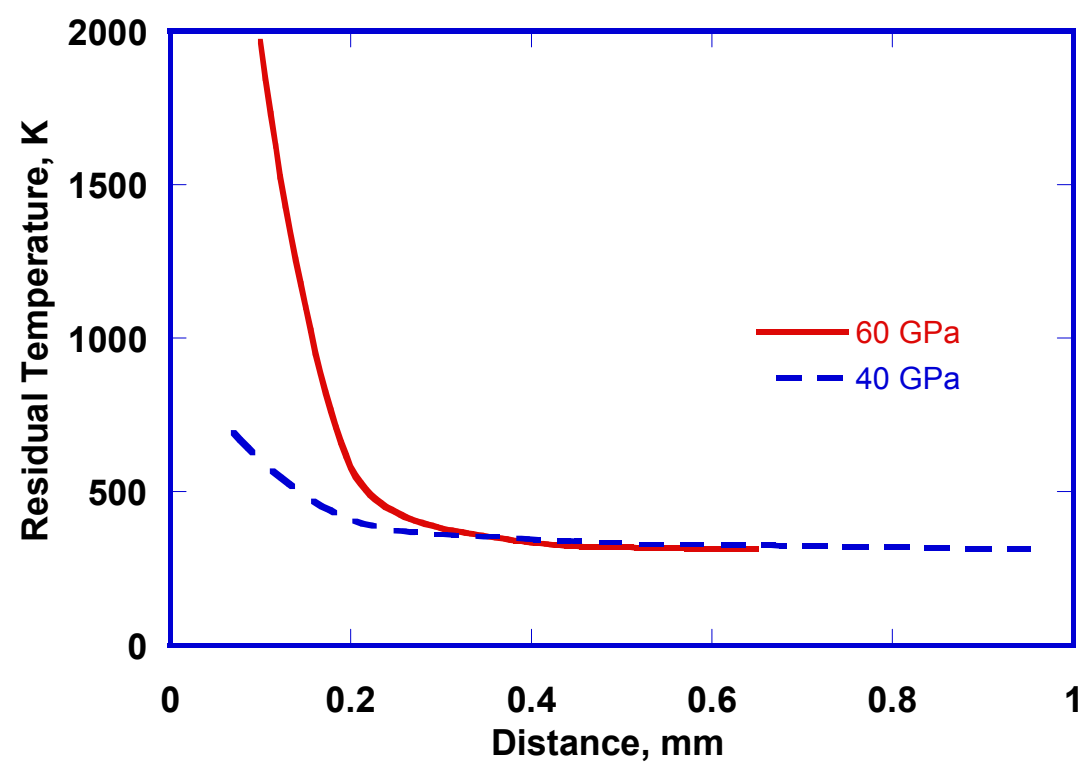

(b)

Figure 9: Residual temperature inside the sample immediately after shock: (a) plate-impact shock; (b) laser shock. 

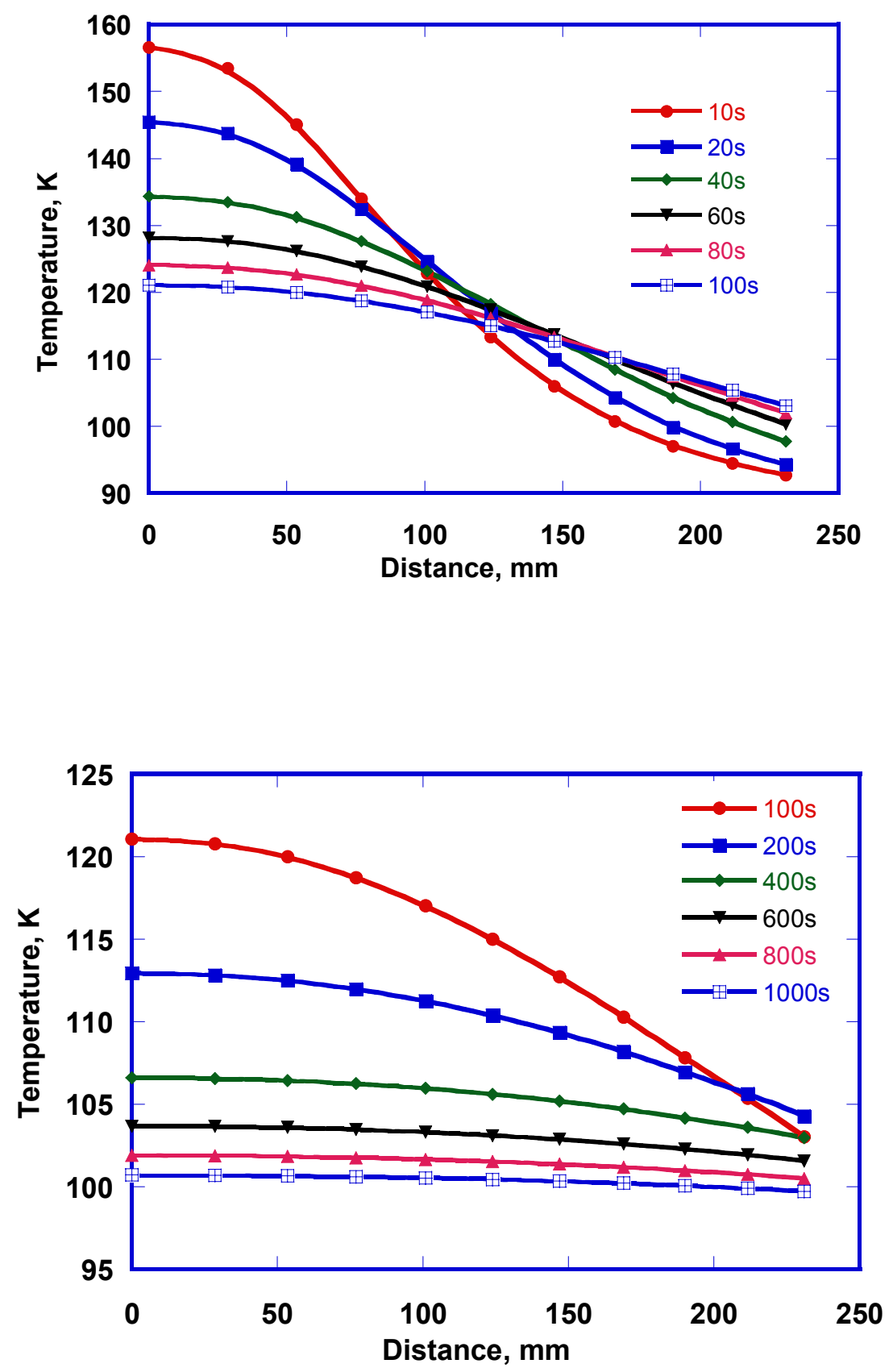

Figure 10: Temperature change for copper plate-impacted at $30 \mathrm{GPa}$. 

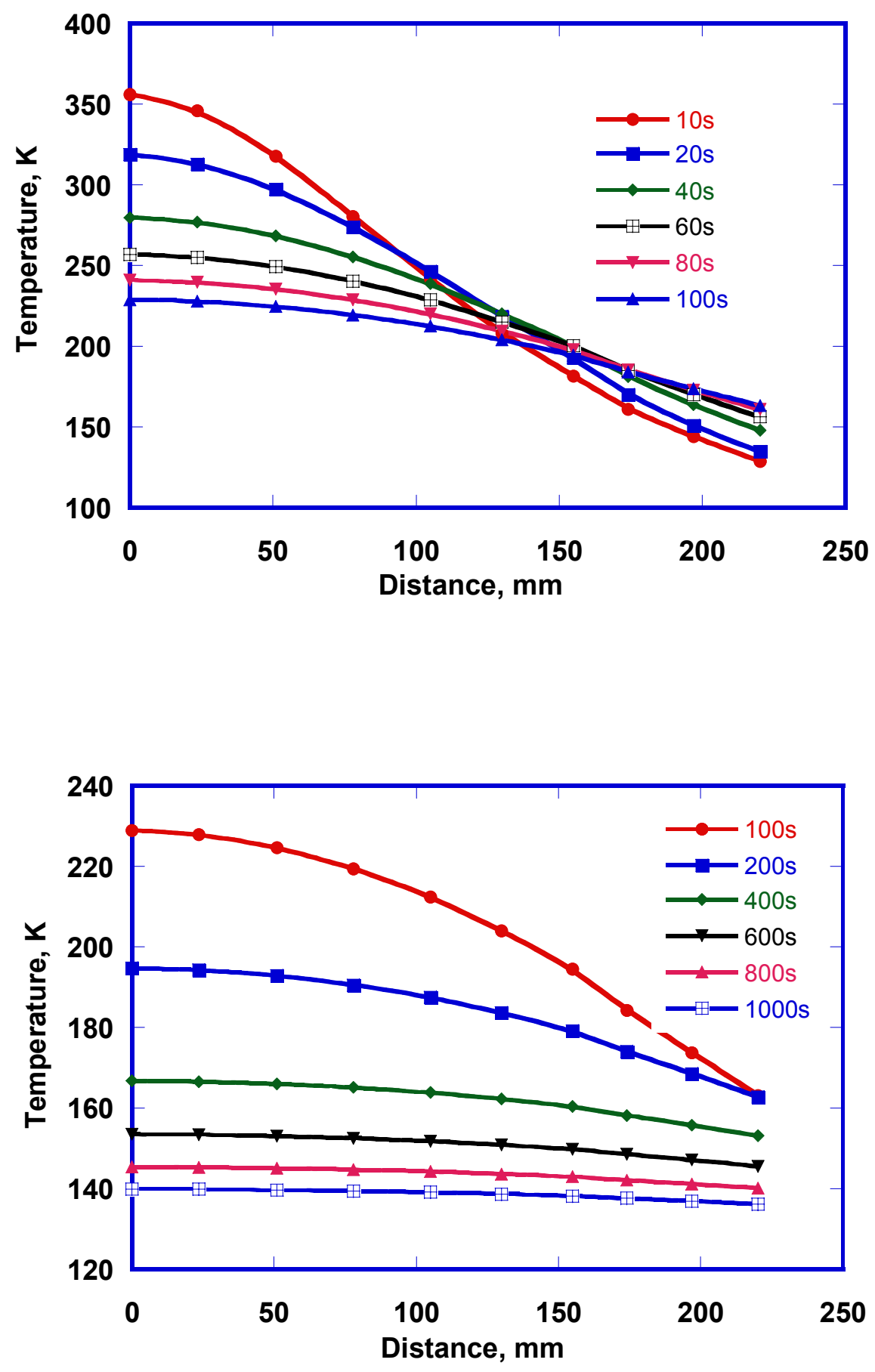

Figure 11: Temperature change for copper plate-impacted at $57 \mathrm{GPa}$. 


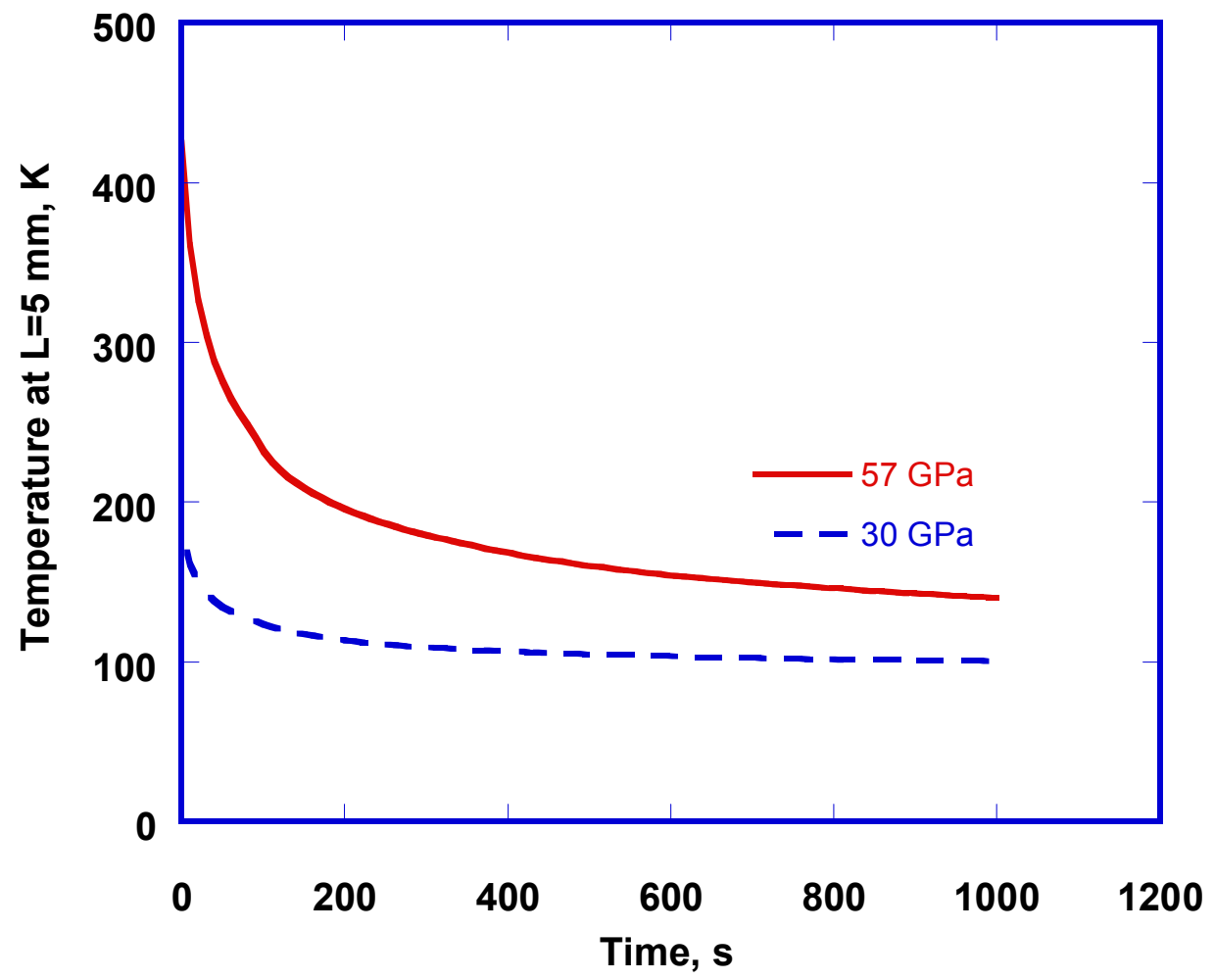

Figure 12: Temperature change for fixed section at $\mathrm{L}=5 \mathrm{~mm}$ along the plate-impacted sample. 


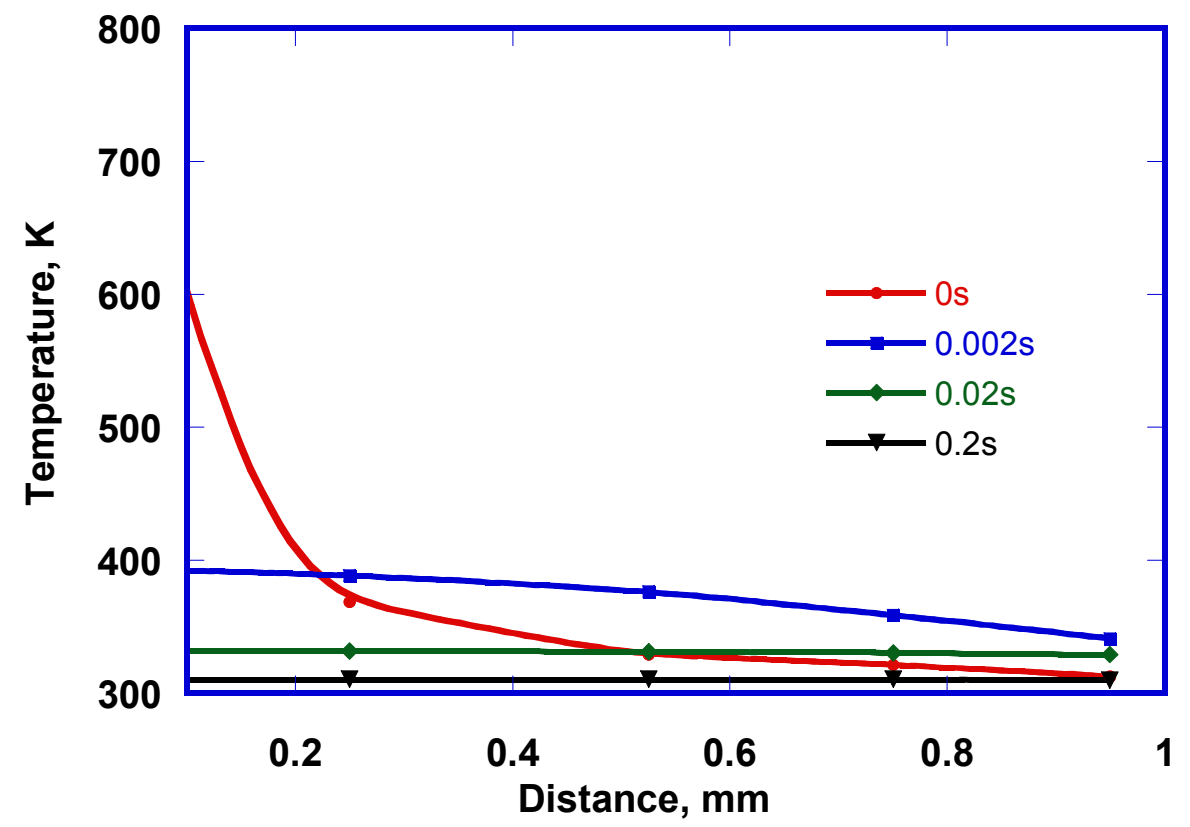

Figure 13: Temperature change in laser shocked copper with $200 \mathrm{~J}$ (40 GPa).

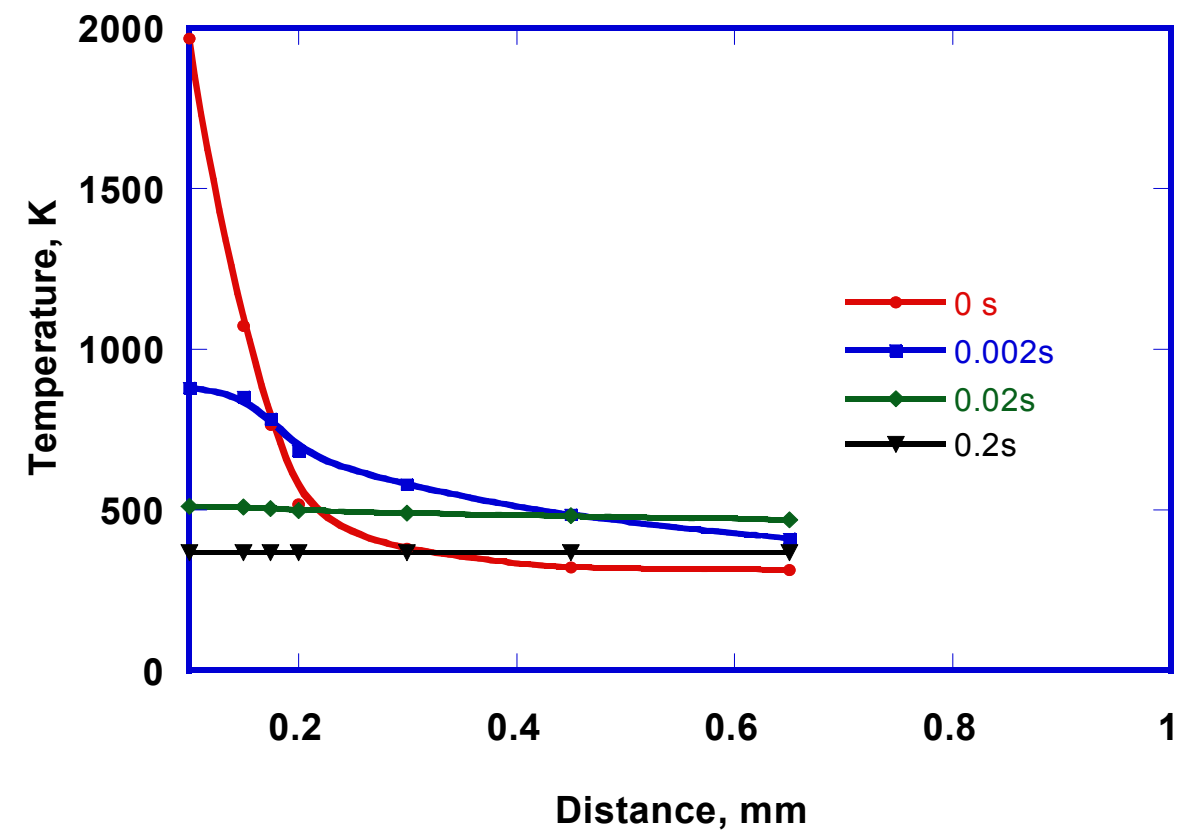

Figure 14: Temperature change in laser shocked copper with $300 \mathrm{~J}$ (60 GPa). 


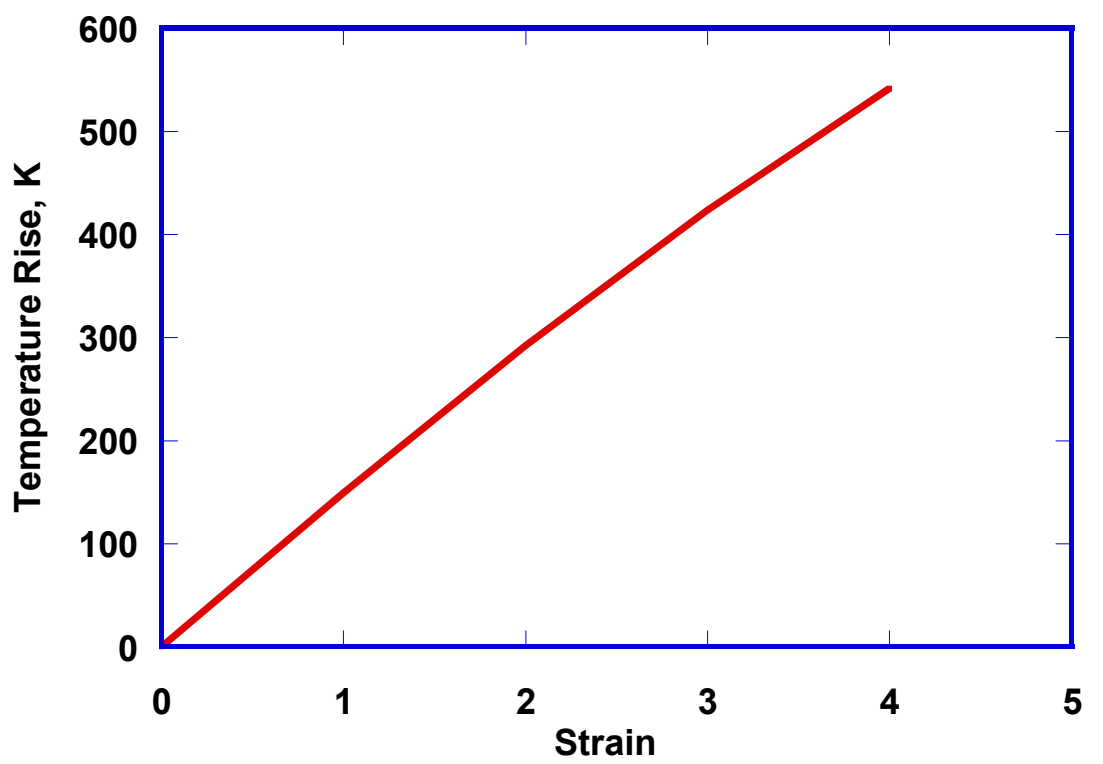

Figure 15: Temperature rise due to plastic deformation. 